Article

\title{
Rietveld Refinement and X-ray Absorption Study on the Bonding States of Lanthanum-Based Perovskite-Type Oxides $\mathrm{La}_{1-x} \mathrm{Ce}_{x} \mathrm{CoO}_{3}$
}

\author{
Duc-Chau Nguyen ${ }^{1}$ (D), Chia-Chin Chu ${ }^{2}$, Aswin Kumar Anbalagan ${ }^{2} \mathbb{D}$, Chih-Hao Lee $2,3, * \mathbb{D}$ \\ and Chia-Seng Chang ${ }^{1, *}$ D \\ 1 Institute of Physics, Academia Sinica, Taipei 115, Taiwan; dcnguyen@gate.sinica.edu.tw \\ 2 Department of Engineering and System Science, National Tsing Hua University, Hsinchu 30013, Taiwan; \\ s101011549@m101.nthu.edu.tw (C.-C.C.); aakumar@mx.nthu.edu.tw (A.K.A.) \\ 3 Institute of Nuclear Engineering and Science, National Tsing Hua University, Hsinchu 30013, Taiwan \\ * Correspondence: chlee@mx.nthu.edu.tw (C.-H.L.); jasonc@phys.sinica.edu.tw (C.-S.C.)
}

\section{check for}

updates

Citation: Nguyen, D.-C.; Chu, C.-C.; Anbalagan, A.K.; Lee, C.-H.; Chang, C.-S. Rietveld Refinement and X-ray Absorption Study on the Bonding States of Lanthanum-Based Perovskite-Type Oxides

$\mathrm{La}_{1-x} \mathrm{Ce}_{x} \mathrm{CoO}_{3}$. Crystals 2022, 12, 50 . https://doi.org/10.3390/

cryst12010050

Academic Editor: Dmitry Medvedev

Received: 6 December 2021

Accepted: 27 December 2021

Published: 30 December 2021

Publisher's Note: MDPI stays neutral with regard to jurisdictional claims in published maps and institutional affiliations.

Copyright: (c) 2021 by the authors. Licensee MDPI, Basel, Switzerland. This article is an open access article distributed under the terms and conditions of the Creative Commons Attribution (CC BY) license (https:/ / creativecommons.org/licenses/by/ $4.0 /)$.

\begin{abstract}
Metal-oxygen bonding of the Ce-doped $\mathrm{LaCoO}_{3}$ system remains largely unexplored despite extensive studies on its magnetic properties. Here, we investigate the structure and local structure of nanoscale $\mathrm{La}_{1-x} \mathrm{Ce}_{x} \mathrm{CoO}_{3}$, with $x=0,0.2$, and 0.4, using the Rietveld refinement and synchrotron $\mathrm{X}$-ray absorption techniques, complemented by topological analysis of experimental electron density and electron energy distribution. The Rietveld refinement results show that $\mathrm{LaCoO}_{3}$ subject to $\mathrm{Ce}$ addition is best interpretable by a model of cubic symmetry in contrast to the pristine $\mathrm{LaCoO}_{3}$, conventionally described by either a monoclinic model or a rhombohedral model. $\mathrm{Ce}^{4+} / \mathrm{Co}^{2+}$ are more evidently compatible dopants than $\mathrm{Ce}^{3+}$ for insertion into the main lattice. X-ray absorption data evidence the partially filled $\mathrm{La} 5 \mathrm{~d}$-band of the pristine $\mathrm{LaCoO}_{3}$ in accordance with the presence of La-O bonds with the shared-type atomic interaction. With increasing $x$, the increased Ce spectroscopic valence and enhanced $\mathrm{La}-\mathrm{O}$ ionic bonding are noticeable. Characterization of the local structures around Co species also provides evidence to support the findings of the Rietveld refinement analysis.
\end{abstract}

Keywords: perovskites; Rietveld refinement; EXAFS; $\mathrm{LaCoO}_{3}$; X-ray absorption; X-ray diffraction

\section{Introduction}

Lanthanum transition metal perovskites (of chemical formula $\mathrm{LaBO}_{3}$ ) have recently attracted tremendous attention due to their pivotal importance from both fundamental and practical points of view. The B-site transition metal coordinates with the six nearest $\mathrm{O}$ atoms, forming an octahedral environment in the bulk of the perovskite structure. On the surface layer, the $\mathrm{BO}_{6}$ octahedron lacks an apical $\mathrm{O}$ atom and exposes the $\mathrm{B}$ site. This active site plays an essential role in facilitating a variety of catalytic reactions in heterogeneous catalysis [1] and electro-catalysis [2]. Therefore, it is beneficial to develop fabrication methods for oxide perovskites with increased specific surface areas and abundant active sites [3]. Cobalt ions can adopt some different oxidation states. On that account, lanthanum cobaltite perovskite $\mathrm{LaCoO}_{3}$ (LCO) endows flexibility in regulating the valence distribution of the Co ion by hole doping or electron doping [4]. This perspective has prompted a burgeoning interest in and extensive studies on the tunable electronic structure of LCO. The objective is to scale down the perovskite structures into the nanoscale regime and incorporate rare earth ions with various valences into these structures to enhance their catalytic activity and expand their applications [5].

The physics of pristine LCO and metal-doped counterparts show an abundance of peculiar properties. The interpretation for the crystal structure of LCO has been a rhombohedral $R-3 c$ symmetry [6,7], where a Jahn-Teller distortion [8] is absent. A monoclinic symmetry of space group $I 2 / a[7,9]$ is also possible, of which the spin state of the $\mathrm{Co}^{3+}$ ion 
is Jahn-Teller active. Accordingly, the rhombohedral lattice preserves one Co-O distance, but the monoclinic structure exhibits a differentiation of $\mathrm{Co}-\mathrm{O}$ bond lengths [9]. There has long been a discussion on the spin states of these compounds, which also involves a conventional picture with the splitting of $t_{2 g}$ and $e_{g}$ orbitals and the double-exchange model with the $e_{g}$ band as the conduction channel $[8,10-17]$. Rare earth metal substitution that alters the oxidation state of Co can also modulate the occupancy of the $e_{g}$-like orbitals and thus the nature of the metal-oxygen bond. Earlier research works on hole-doped LCO found a quasi-stable spin state crossing the Fermi level [15] and that the $e_{g}$ states interact with $\mathrm{O} 2 p$ states, spreading over a wide energy range [18]. These findings elicit the same line of inquiry on cerium doping to understand the changes in the metal-oxygen bonding properties associated with the electron-doped LCO.

Previous studies on the Ce-doped LCO system have mainly explored the magnetic properties but have paid little attention to the metal-oxygen bonding [19-22]. These works demonstrate that Ce-doping can induce and stabilize the intermediate spin or low-spin high-spin configurations and hint that a high content of dopants may increase the occupancy of the $e_{g}$-like states. However, up-to-date studies remain scarce on the possible phase transformation of Ce-doped LCO with high Ce contents and the connection with changes in the local structure. In particular, the details of how Ce-doping modifies the atomic interactions of metal-oxygen bonding, especially the La-O bonding, are still largely unexplored.

In this work, we report on the structure and local structure of nanoscale $\mathrm{La}_{1-x} \mathrm{Ce}_{x} \mathrm{CoO}_{3}$ where $x$ is the nominal degree of substitution and $x=0,0.2$, and 0.4 . We use the Rietveld refinement method to fit various models of the main lattice and valence and fraction of $\mathrm{Ce}$ dopants to the experimental X-ray diffraction (XRD) data. For clarity, such notations as $\mathrm{La}_{1-s} \mathrm{Ce}_{s} \mathrm{CoO}_{3}$ or $\mathrm{La}_{1-s}^{3+} \mathrm{Ce}_{s}^{4+} \mathrm{Co}_{1-s}^{3+} \mathrm{Co}_{s}^{2+} \mathrm{O}_{3}$ will refer to the main lattice, depending on the form of Ce dopants. The data do not precisely point out to what extent $\mathrm{Ce}$ can be present in the LCO lattice. Nevertheless, we find Ce insertion into the main phase plausible and the $\mathrm{Ce}^{4+} / \mathrm{Co}^{2+}$ ions more favorable than $\mathrm{Ce}^{3+}$ ions as dopants. Our estimates of the $\mathrm{Ce}$ valence of total Ce species in the sample are achievable based on X-ray absorption near edge structure (XANES) data at $\mathrm{Ce} L_{3}$-edge. We illuminate the noticeable change of XANES spectra at $\mathrm{La} \mathrm{L}_{3}$-edge as an effect of Ce-doping by conducting the topological analysis of the experimental electron densities and mapping the corresponding electronic energy distributions. We also present an in-depth investigation on the extended X-ray absorption structure (EXAFS) by fitting to data using the models built from the Rietveld refinement results. Building fitting models to EXAFS spectra of these samples is highly challenging due to three issues: (1) each sample involves two scattering phases, (2) the secondary scattering phase, realized as a $\mathrm{Co}_{3} \mathrm{O}_{4}$-like phase, has two inequivalent adsorbing sites, and (3) handling dopants, which is an arcane manipulation. Hence, we needed a sophisticated strategy in EXAFS data analysis, as discussed in the following sections.

\section{Experiments}

$\mathrm{La}_{1-x} \mathrm{Ce}_{x} \mathrm{CoO}_{3}$ perovskites were synthesized via the sol-gel method [23] from metal nitrates, with citric acid as the chelating agent (Carl Roth $\mathrm{GmbH}$, Karlsruhe, Germany). The precursors were dewatered at $80^{\circ} \mathrm{C}$ until gel formation, then dried overnight at $100{ }^{\circ} \mathrm{C}$ in vacuum, and finally milled and calcined at $700{ }^{\circ} \mathrm{C}$ in air for $5 \mathrm{~h}$. Crystal structures of the obtained products were investigated by X-ray diffraction (XRD) using a PANalytical X-Pert Pro Diffractometer (Malvern Panalytical, Malvern, UK) with $\mathrm{Cu} \mathrm{K} \alpha$ radiation $(\lambda=1.540598 \AA)$. The data were collected in the angular range of $19^{\circ} \leq 2 \theta \leq 80^{\circ}$, with scanning steps of $0.01^{\circ}$ and a cumulative time of $15 \mathrm{~s} / \mathrm{step}$.

X-ray absorption spectroscopy (XAS) data at the Co K edge (7709 eV), La $L_{3}$ edge $(5483 \mathrm{eV})$, and $\mathrm{Ce} L_{3}$ edge $(5723 \mathrm{eV})$ were measured at room temperature at the BL-07A and BL-17C [24] beamlines of the Taiwan Light Source. The monochromator was detuned by $20 \%$ to suppress higher harmonic radiation. Energy calibration was performed by assigning the position of the first inflection point of the absorption spectrum of a Co foil to $7.709 \mathrm{keV}$. 
The same procedure was applied to a $V$ foil for calibrating the initial energy at the $V L_{3}$ edge to $5.465 \mathrm{keV}$. Because pure La and Ce metals are oxidized easily, we used this alternative calibration method to prepare for the XAS measurements at La $L_{3}$ edge and Ce $L_{3}$ edge. The incident $\left(\mathrm{I}_{0}\right)$ and the transmitted beam $\left(\mathrm{I}_{t}\right)$ were measured using sealed ion chambers, with a combination of gases for appropriate absorption. The XAS data were recorded up to $16 \AA^{-1}$ in $k$-space beyond the absorption edge, with a constant step of $\Delta k=0.06 \AA^{-1}$. The dwell time was adjusted progressively from 4 to $16 \mathrm{~s}$ based on how large the scanning energy was compared to the absorption edge. Four scans were collected for each absorption edge of interest.

\section{Data Analysis}

Quantitative analysis Rietveld refinement of the XRD data was carried out using the Marquardt least-squares algorithm, implemented in the Materials Analysis Using Diffraction (MAUD) software package (Luca Lutterotti, Trento, Italy) [25]. We performed Rietveld full-spectrum fitting for various models to determine backgrounds, unit-cell parameters, weight percentages, and microstructure for the individual phases present in each sample. Regarding the main lattice, we considered six initial models, including three different perovskite structures and two forms of dopants. The three structures are rhombohedral, monoclinic, and cubic, described by the space groups $R-3 c: R$ (No. 167) [26], I12/a1 (No. 15) [7], and Pm-3m (No. 221) [27], respectively. The two cases of dopants were $\mathrm{Ce}^{3+}$ and $\mathrm{Ce}^{4+}$. For the case $\mathrm{Ce}^{4+}$, the cobalt ions were set to adopt $\mathrm{Co}^{2+}$ for charge compensation. In addition, we introduced $s$, the fraction of cerium dopants, into the main lattice as $\mathrm{La}_{1-s} \mathrm{Ce}_{s} \mathrm{CoO}_{3}$ or $\mathrm{La}_{1-s}^{3+} \mathrm{Ce}_{s}^{4+} \mathrm{Co}_{1-s}^{3+} \mathrm{Co}_{s}^{2+} \mathrm{O}_{3}$ and performed a series of fits, altering the value of $s$ from 0 to 1 by an increment of 0.05 . We also considered a secondary phase as cubic $\mathrm{Co}_{3} \mathrm{O}_{4}$ (space group $F d-3 m$, No. 227) [28] for the $x=0$ sample, and as cubic $\mathrm{CeO}_{2}$ (space group Fm3m, No. 225) [29] for the $x=0.2$ and $x=0.4$ samples. The quality of Rietveld fits was evaluated based on both the visual inspection of observed and calculated patterns and the comparison of the values of discrepancy indices. The most straightforward index is the weight profile $R$-factor $\left(R_{\mathrm{wp}}\right)$ [30].

X-ray absorption near edge structure (XANES) spectra at the $\mathrm{Ce} L_{3}$-edge of $\mathrm{La}_{1-x} \mathrm{Ce}_{x} \mathrm{CoO}_{3}$ were analyzed by the conventional superposition method, as in some earlier works [31-34]. We performed the first derivative test to find the extremum points. The result gave two local maximum points and one minimum point, corresponding to two component peaks and the valley between them. We also determined an inflection point by inspecting the second derivative. In total, three line-shapes were used in a least-squares fit to the XANES data: two Gaussian line-shape functions to describe the localized final states and an arctangent edge jump function to represent the transition into continuum states.

To explain the observed XANES spectra at the La $L_{3}$ edge, reported in the next part of this paper, we put forward a comprehensive characterization of La-O bonding in the main lattice phase of three lattice models. First, we reconstructed the crystal electron density directly, based on the results of the Rietveld refinement for the XRD data [35]. The spatial resolution of the model electron density was $0.042 \AA$. The model electron density provided us with the topological analysis of the intermolecular interactions between La and $\mathrm{O}$. We then calculated the electron energy distribution from the experimental electron density, which is a straightforward way to recognize the atomic interaction type of $\mathrm{La}-\mathrm{O}$ in the lattice model of interest. The theory of this approach is described in detail in the work of Tsirelson [36]. Utilities of the Visualization for Electronic and Structural Analysis (VESTA) software (Koichi Momma, Ibaraki, Japan) [37] were used for model visualizations and two-dimensional data display.

The EXAFS data at the Co K-edge were analyzed using the Demeter package [38]. We performed XAS data processing in the Athena program. The multi-step procedure resulted in the extracted EXAFS oscillation and Fourier transform for each XAS spectrum, which was then fitted in the Artemis program. Forward Fourier transformations of the EXAFS data were performed in the $\Delta k$ range of 3.3-16 $\AA^{-1}$ using the Kaiser-Bessel window. 
We conducted an unconventional approach $[39,40]$ to include a mixture of two scattering phases in each sample. Theoretical scattering paths, as listed in Table 1, were generated with the structural parameters obtained from the Rietveld analyses for the XRD data. For the sample with $x=0$, we assumed a mixture of a rhombohedral main lattice and a cubic $\mathrm{Co}_{3} \mathrm{O}_{4}$-like phase. For both the $x=0.2$ and $x=0.4$ samples, we considered a combination of a cubic main lattice and a cubic $\mathrm{Co}_{3} \mathrm{O}_{4}$-like phase. To interpret the introduced structure of $\mathrm{Co}_{3} \mathrm{O}_{4}$ in a manner compatible with the Demeter program, we transformed the non-standard setting $F d-3 m: 1$ [28] into the standard $F d-3 m$ using a shift vector of $(1 / 8,1 / 8$, $1 / 8)$. The list of potentials was complemented with a new potential index and the atomic number for Ce. Changes of La tags to be Ce in the list of atom coordinates were also done in addition to appropriate adjustment of the corresponding potential index before running the FEFF calculation. We aimed to deal with the information-limited problem to fit for a $\Delta R$ range of $1-4 \AA$. The relation $N \approx(2 / \pi) \Delta R \times \Delta k$ suggested approximately 24 independent parameters. Normal "strict degeneracy" was used for the FEFF calculation for the main scattering phase, but the so-called "fuzzy degeneracy" [41] with a margin of $0.03 \AA$ was applied for the aggregate FEFF calculation over two sites of the $\mathrm{Co}_{3} \mathrm{O}_{4}$-like scattering phase. The number of scattering paths was therefore reduced substantially to only three single scattering paths (SS), as listed in Tables 2 and 3 for the secondary scattering phase. We also included two multiple scattering paths in the model for the main lattice, that is, a three-legged path @O1.1Co1.1@ and a four-legged path @O1.1Co1.1O1.1@. In a cubic main phase, these forward scattering paths are perfectly focused and do not put in new free parameters to a fit [39]. In a rhombohedral main phase, these paths are partially focused. Since the angle with the vertex at Co is only $8.5^{\circ}$ [39], as determined from the result of the Rietveld refinement, both paths can be treated as the same as the single-scattering path $@$ Co1.1@. However, we found that the quality of the fit could be statistically improved by strictly defining the $\Delta R_{j}$ of the path @O1.1Co1.1@ as $\left(2 \Delta R_{O 1.1}-\Delta R_{C o 1.1}\right) / 2$, as shown in Table 2. We used an expansion factor $\alpha$ and the built-in $R_{\text {eff }}$ value to describe the isotropic change of all paths of any cubic phase. The variable for $\Delta R_{j}$ of the $\mathrm{Co}_{3} \mathrm{O}_{4}$-like scattering phase is expressed as $\alpha R_{\text {eff }}$ in Table 2. In Table 3, the settings $\alpha_{1} R_{\text {eff }}$ and $\alpha_{2} R_{\text {eff }}$ account for the change in distance of all paths of the main lattice and the secondary phase, respectively.

Table 1. Structural information used as inputs for FEFF calculations (Rhombo = Rhombohedral).

\begin{tabular}{cccc}
\hline$x$ & Phase & $\begin{array}{c}\text { Space Group } \\
\text { Name, Number }\end{array}$ & Unit Cell \\
\hline 0 & Rhombo LaCoO$_{3}$ & $\mathrm{R}-3 \mathrm{c}, 167$ & $a=b=c=5.3855(\AA), \alpha=\beta=\gamma=60.727\left(^{\circ}\right)$ \\
0 & $\mathrm{Co}_{3} \mathrm{O}_{4}$ & $\mathrm{Fd}-3 \mathrm{~m}, 227$ & $a=b=c=8.0796(\AA), \alpha=\beta=\gamma=90.000\left(^{\circ}\right)$ \\
0.2 and 0.4 & $\mathrm{Cubic} \mathrm{La}_{1-s} \mathrm{Ce}_{s} \mathrm{CoO}_{3}$ & $\mathrm{Pm}-3 \mathrm{~m}, 221$ & $a=b=c=3.8817(\AA), \alpha=\beta=\gamma=90.000\left(^{\circ}\right)$ \\
0.2 and 0.4 & $\mathrm{Co}_{3} \mathrm{O}_{4}$ & $\mathrm{Fd}-3 \mathrm{~m}, 227$ & $a=b=c=8.0796(\AA), \alpha=\beta=\gamma=90.000\left(^{\circ}\right)$ \\
\hline
\end{tabular}

Note: $s=0,0.125,0.25,0.375,0.5,0.625,0.75,0.875$, and 1 .

Regarding all the above-mentioned details, we parametrized 14 variables for $\sigma_{j i}^{2}$ $\Delta E_{0}^{j}$, and $\Delta R_{j}$ for the case $x=0$ and 10 variables for the cases $x=0.2$ and $x=0.4$, as displayed in Tables 2 and 3, respectively. Additionally, there was one more variable not shown in these tables, which accounts for the amplitude term $S_{0}^{2}$ for each case of $x$. The amplitudes of the main scattering phase and the secondary phase correlate by the formula $S_{0}^{2}=S_{\text {main }}^{2}+S_{\text {secondary }}^{2}$. We implemented fits to the data simultaneously with multiple $k$ weightings (i.e., $k$ to $k^{3}$ ). Phase correction for the radial distance was made based on the $\mathrm{Co}-\mathrm{O}$ pair of the main scattering phase. 
Table 2. EXAFS model for Co K-edge spectrum of the $x=0$ sample based on the two-phase mixture. $\mathrm{Co}_{3} \mathrm{O}_{4}$ has two inequivalent absorbing sites. The symbol @ denotes the absorbing atom.

\begin{tabular}{|c|c|c|c|c|c|c|}
\hline Scattering Phase & Scattering Path & $N_{j i}$ & $R_{\text {eff }}(\AA)$ & $\sigma_{j i}^{2}\left(\AA^{2}\right)$ & $\Delta E_{0}^{j}(\mathrm{eV})$ & $\Delta R_{j}(\AA)$ \\
\hline Rhombo $\mathrm{LaCoO}_{3}$ & @01.1@ & 6 & 1.936 & $\sigma_{O 11}^{2}$ & $\Delta E_{0}^{1}$ & $\Delta R_{O 1.1}$ \\
\hline Rhombo $\mathrm{LaCoO}_{3}$ & @ La1.1@ & 2 & 3.280 & $\sigma_{L a 1.1}^{2}$ & $\Delta E_{0}^{1}$ & $\Delta R_{L a 1.1}$ \\
\hline Rhombo $\mathrm{LaCoO}_{3}$ & @La1.2@ & 6 & 3.328 & $\sigma_{L a 1.1}^{2}$ & $\Delta E_{0}^{1}$ & $\Delta R_{L a 1.2}$ \\
\hline Rhombo $\mathrm{LaCoO}_{3}$ & @ Co1.1@ & 6 & 3.829 & $\sigma_{\text {Cho1. }}^{2}$ & $\Delta E_{0}^{1}$ & $\Delta R_{C o 1.1}$ \\
\hline Rhombo $\mathrm{LaCoO}_{3}$ & @ O1.1Co1.1@ & $\Sigma=12$ & 3.850 & $\sigma_{C 01.1}^{2}$ & $\Delta E_{0}^{1}$ & $=\left(2 \Delta R_{O 1.1}-\Delta R_{C o 1.1}\right) / 2$ \\
\hline Rhombo $\mathrm{LaCoO}_{3}$ & @ O1.1Co1.1O1.1@ & $\Sigma=6$ & 3.871 & $\sigma_{C o 1.1}^{2}$ & $\Delta E_{0}^{1}$ & $\Delta R_{\text {Co1.1 }}$ \\
\hline $\mathrm{Co}_{3} \mathrm{O}_{4}$ & @ O_SS@ & 5.333 & 1.923 & $\sigma_{O S S}^{2}$ & $\Delta E_{0}^{2}$ & $\alpha R_{\mathrm{eff}}$ \\
\hline $\mathrm{Co}_{3} \mathrm{O}_{4}$ & @ Co_SS1 @ & 4 & 2.857 & $\sigma_{\text {Co SS1 }}^{2} 30$ & $\Delta E_{0}^{2}$ & $\alpha R_{\text {eff }}$ \\
\hline $\mathrm{Co}_{3} \mathrm{O}_{4}$ & @ Co_SS2 @ & 8 & 3.350 & $\sigma_{\text {Co SS2 }}^{2}$ & $\Delta E_{0}^{2}$ & $\alpha R_{\text {eff }}$ \\
\hline
\end{tabular}

Table 3. EXAFS model for Co K-edge spectra of the $x=0.2$ and $x=0.4$ samples based on the two-phase mixture. $\mathrm{Co}_{3} \mathrm{O}_{4}$ has two inequivalent absorbing sites. The symbol @ denotes the absorbing atom.

\begin{tabular}{|c|c|c|c|c|c|c|}
\hline Scattering Phase & Scattering Path & $N_{j i}$ & $R_{\text {eff }}(\AA)$ & $\sigma_{j i}^{2}\left(\AA^{2}\right)$ & $\Delta E_{0}^{j}(\mathrm{eV})$ & $\Delta R_{j}(\AA)$ \\
\hline Cubic $\mathrm{La}_{1-s} \mathrm{Ce}_{s} \mathrm{CoO}_{3}$ & @ O1.1@ & 5.4 & 1.941 & $\sigma_{O 1}^{2}$ & $\Delta E_{0}^{1}$ & $\alpha_{1} R_{\text {eff }}$ \\
\hline Cubic $\mathrm{La}_{1-s} \mathrm{Ce}_{s} \mathrm{CoO}_{3}$ & @ La1.1@ & $8(1-s)$ & 3.362 & $\sigma_{L a 1}^{2}$ & $\Delta E_{0}^{1}$ & $\alpha_{1} R_{\text {eff }}$ \\
\hline Cubic $\mathrm{La}_{1-s} \mathrm{Ce}_{s} \mathrm{CoO}_{3}$ & @ Ce1.1@ & $8 s$ & 3.362 & $\sigma_{L a 1}^{2}$ & $\Delta E_{0}^{1}$ & $\alpha_{1} R_{\text {eff }}$ \\
\hline Cubic $\mathrm{La}_{1-s} \mathrm{Ce}_{s} \mathrm{CoO}_{3}$ & @ Co1.1@ & 6 & 3.882 & $\sigma_{\mathrm{Co}}^{2}$ & $\Delta E_{0}^{1}$ & $\alpha_{1} R_{\text {eff }}$ \\
\hline Cubic $\mathrm{La}_{1-s} \mathrm{Ce}_{s} \mathrm{CoO}_{3}$ & @ O1.1Co1.1@ & $\Sigma=12$ & 3.882 & $\sigma_{C o 1.1}^{2}$ & $\Delta E_{0}^{1}$ & $\alpha_{1} R_{\text {eff }}$ \\
\hline Cubic $\mathrm{La}_{1-s} \mathrm{Ce}_{s} \mathrm{CoO}_{3}$ & @ O1.1Co1.1O1.1@ & $\Sigma=6$ & 3.882 & $\sigma_{C o 1.1}^{2}$ & $\Delta E_{0}^{1}$ & $\alpha_{1} R_{\text {eff }}$ \\
\hline $\mathrm{Co}_{3} \mathrm{O}_{4}$ & @O_SS@ & 5.333 & 1.923 & $\sigma_{O S}^{2}$ & $\Delta E_{0}^{2}$ & $\alpha_{2} R_{\text {eff }}$ \\
\hline $\mathrm{Co}_{3} \mathrm{O}_{4}$ & @ Co_SS1 @ & 4 & 2.857 & $\sigma_{C o S S 1}^{2}$ & $\Delta E_{0}^{2}$ & $\alpha_{2} R_{\text {eff }}$ \\
\hline $\mathrm{Co}_{3} \mathrm{O}_{4}$ & @ Co_SS2 @ & 8 & 3.350 & $\sigma_{\text {CoSS2 }}^{2}$ & $\Delta E_{0}^{2}$ & $\alpha_{2} R_{\text {eff }}$ \\
\hline
\end{tabular}

Note: $s=0,0.125,0.25,0.375,0.5,0.625,0.75,0.875$, and 1 .

\section{Results and Discussion}

Figure 1 shows $R_{\mathrm{wp}}$ as a function of $s$ for 252 fits to the experimental XRD data of $\mathrm{La}_{1-x} \mathrm{Ce}_{x} \mathrm{CoO}_{3}$. It is worth repeating that $s$ accounts for the atomic percent of $\mathrm{Ce}$ in $\mathrm{La}_{1-s} \mathrm{Ce}_{s} \mathrm{CoO}_{3}$, the main lattice. Such use of $s$ is to conveniently tackle the question as to whether $\mathrm{Ce}$ is present and to what extent in the host lattice. The inquiry emerges from a prior admission [20] for an already formed secondary phase, $\mathrm{CeO}_{2}$, if the nominal composition of $\mathrm{Ce}$ is higher than 0.03 . We find that the two-phase model results in statistically better refinement than the single-phase model. All the resultant $R_{\mathrm{wp}}$ are lower than $15 \%$, which meets the requirement for an adequate Rietveld refinement. Both cases of $x$ reveal that when combining $\mathrm{Ce}^{4+}$ and $\mathrm{Co}^{2+}$ as substitutes for $\mathrm{La}^{3+}$, the $R_{\mathrm{wp}}$ are lower than those where the dopants are $\mathrm{Ce}^{3+}$, highlighting the importance of the charge compensation by $\mathrm{Co}^{2+}$. However, since the $R_{\mathrm{wp}}$ changes linearly and nearly monotonically with $s$, the absolute extent of Ce insertion into the host lattice remains inconclusive. Further, for $x=0.2$, the $R_{\mathrm{wp}}$ regarding each form of dopant are comparable among the three space groups of the main lattice. For $x=0.4$, respecting space groups of the main lattice, the $R_{\mathrm{wp}}$ for cubic $P m-3 m$ are lower than those for rhombohedral $R-3 c: R$ and monoclinic I12/a1, which holds for both forms of dopants under consideration. 

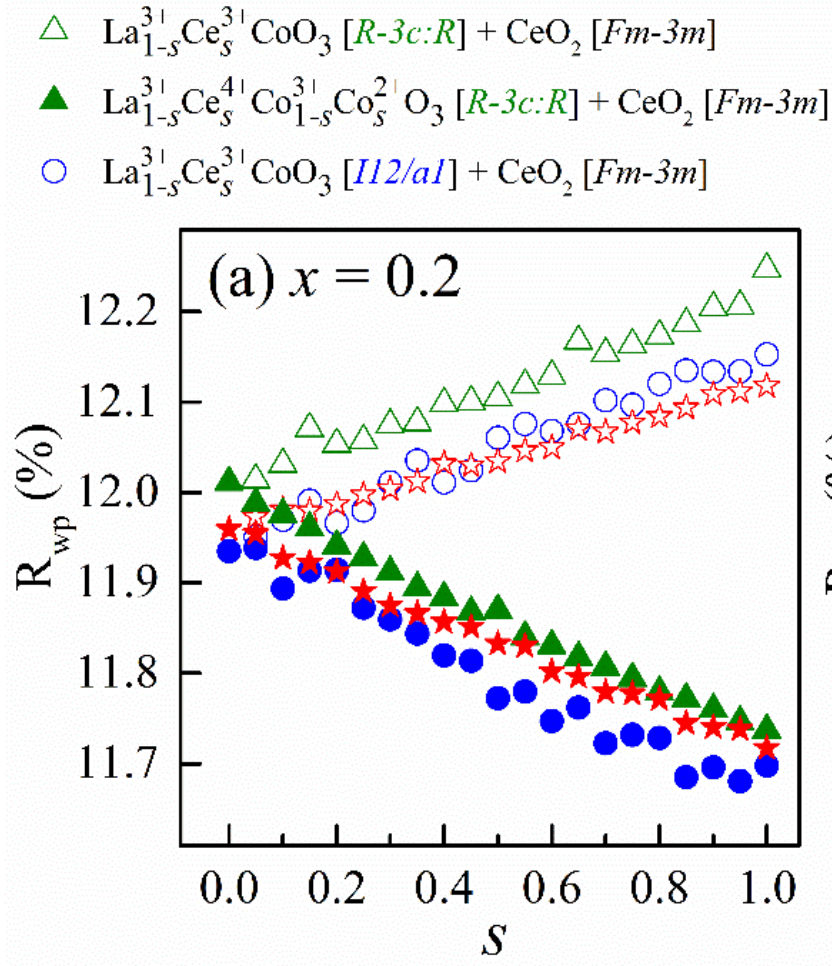
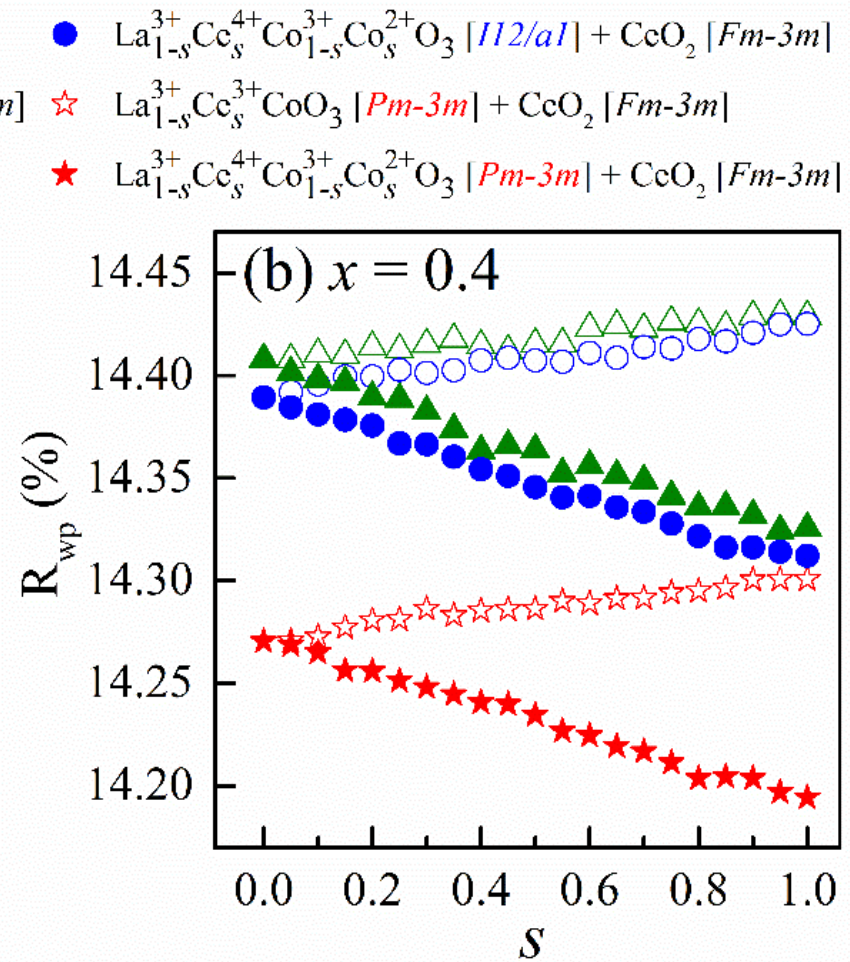

Figure 1. Weighted profile $R$-factor as a function of $s$, the fraction of cerium dopants in the main phase of $\mathrm{La}_{1-x} \mathrm{Ce}_{x} \mathrm{CoO}_{3}$ with (a) $x=0.2$ and (b) $x=0.4$. In these Rietveld fits, six models consider three different space-groups of the main phase and two forms of dopants. The three space groups are $R-3 c$ : $R$ (rhombohedral), I12/a1 (monoclinic), and $P m-3 m$ (cubic). The two cases of cerium dopants are $\mathrm{Ce}^{3+}$ and $\mathrm{Ce}^{4+} / \mathrm{Co}^{2+}$. The secondary phase, $\mathrm{CeO}_{2}$, has a face-centered cubic space group of $\mathrm{Fm}-3 \mathrm{~m}$.

Figure 2 displays some selected Rietveld refined XRD patterns along with the corresponding Bragg positions. It is noteworthy that the cubic space group Pm-3m applied for the main lattice does not result in a successful fit for $x=0$ and so is not reported. Figure $2 a, b$ is for the case $x=0$, for which the $R$-factors are 0.1343 and 0.1344 , corresponding to the main lattice as rhombohedral $R-3 c: R$ and monoclinic I12/a1, respectively. The fact that the two spectra are identical and have equivalent $R$-factors is consistent with the indistinguishable XRD patterns [7] found previously between the two assumed space groups. Due to this similarity, we show only the typical spectra of monoclinic I12/a1 to compare with the cubic $P m-3 m$ in Figure 2c,d for $x=0.2$ and in Figure 2e,f for $x=0.4$. The graphic analysis of these patterns brings about an agreement with the $R_{\mathrm{wp}}$ reported in Figure 1 . However, the vertical bars representing positions of the Bragg peaks located at the bottom of each figure indicate the disappearance of many peaks for the monoclinic I12/a1 compared to the cubic $P m-3 m$. These aspects, together with the discussion for Figure 1, show that the cubic model performs best for the interpretation of the main lattice in the crystals of Ce-doped LCO.

Figure 3 shows the refined lattice parameters from the same fits that resulted in the $R_{\mathrm{wp}}$ in Figure 1. The refined parameters as a function of $s$ for the main lattice in Figure $3 \mathrm{a}-\mathrm{g}$ are explicitly different between the two cases of $x$, but only within the error bars for the secondary phase in Figure $3 \mathrm{~h}-\mathrm{j}$. In Figure $3 \mathrm{a}$, values for the lattice parameter $a$ are greater for $x=0.4$ than for $x=0.2$, but those for different forms of dopants in each $x$ show no explicit difference. This scenario demonstrates that the expansion of the cubic lattice governed by the doping effect dominates the influence of the intrinsic properties of the dopants, such as the atomic sizes. It is clear from Figure $3 b, c$ that both the lattice length $a$ and angle $\alpha$ increase with increasing $x$, indicating the simultaneous doping-derived augmentation and tilting of the rhombohedral lattice. Finally, the lattice parameters of the monoclinic main phase in Figure $3 \mathrm{~d}-\mathrm{g}$ show mixed trends with increasing $x: a, b$, and $\beta$ increase, but $b$ decreases. 

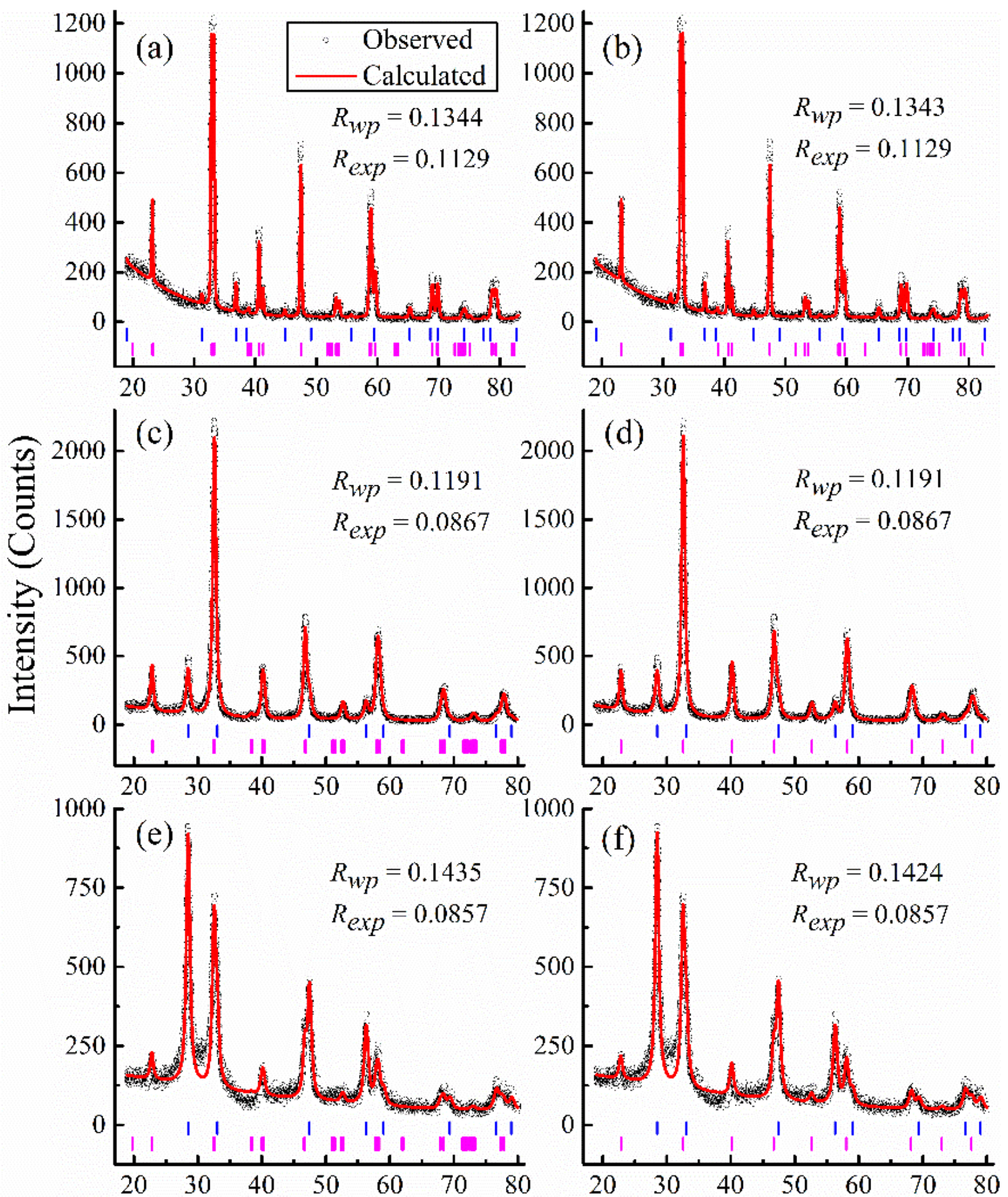

Bragg angle (2 theta, degrees)

Figure 2. Rietveld refinement patterns of XRD data for $\mathrm{La}_{1-x} \mathrm{Ce}_{x} \mathrm{CoO}_{3}:(\mathbf{a}, \mathbf{b}) x=0,(\mathbf{c}, \mathbf{d}) x=0.2$, and $(\mathbf{e}, \mathbf{f}) x=0.4$. Vertical lines at the bottom of each sub-figure represent positions of Bragg peaks of the main phase (lower lines) and the secondary phase (upper lines). Phase and [space group] for each subfigure are as follows: (a) $\mathrm{LaCoO}_{3}[I 12 / a 1]+\mathrm{Co}_{3} \mathrm{O}_{4}$ [Fd-3m:1], (b) $\mathrm{LaCoO}_{3}[R-3 c: R]+\mathrm{Co}_{3} \mathrm{O}_{4}$ [Fd-3m:1], (c) $\mathrm{La}_{0.8}^{3+} \mathrm{Ce}_{0.2}^{4+} \mathrm{Co}_{0.8}^{3+} \mathrm{Co}_{0.2}^{2+} \mathrm{O}_{3}[I 12 / a 1]+\mathrm{CeO}_{2}[F m-3 m]$, (d) $\mathrm{La}_{0.8}^{3+} \mathrm{Ce}_{0.2}^{4+} \mathrm{Co}_{0.8}^{3+} \mathrm{Co}_{0.2}^{2+} \mathrm{O}_{3}[P m-3 m]+\mathrm{CeO}_{2}[\mathrm{Fm}-$ $3 m],(\mathbf{e}) \mathrm{La}_{0.6}^{3+} \mathrm{Ce}_{0.4}^{4+} \mathrm{Co}_{0.6}^{3+} \mathrm{Co}_{0.4}^{2+} \mathrm{O}_{3}[I 12 / a 1]+\mathrm{CeO}_{2}[\mathrm{Fm}-3 m]$, and (f) $\mathrm{La}_{0.6}^{3+} \mathrm{Ce}_{0.4}^{4+} \mathrm{Co}_{0.6}^{3+} \mathrm{Co}_{0.4}^{2+} \mathrm{O}_{3}[P m-3 m]+$ $\mathrm{CeO}_{2}[\mathrm{Fm}-3 \mathrm{~m}]$. 
Additionally, Table 4 provides the weight percent and details of microstructures for both phases involved in each fit. Notably, the crystallite sizes of the Ce-doped LCO are about six times smaller than the pristine LCO, regardless of the models used in the fits. This shrinkage complies with the use of the dopants and the sol-gel method for sample preparation. Table 5 summarizes the average lattice parameters to give a comparison among different $x$. Table 6 tabulates selected bond lengths obtained from the Rietveld refinement and the charge fractions received by each coordination atom, some of which are illustrative in Figure 4. Noticeably, the Co-O bond length is of a six-fold degeneracy in the rhombohedral main phase, while that in the monoclinic main phase differentiates into three pairs of $\mathrm{Co}-\mathrm{O}$ bond lengths. This finding is consistent with the fact that the Jahn-Teller distortion is missing in the rhombohedral lattice and exists in the monoclinic lattice.
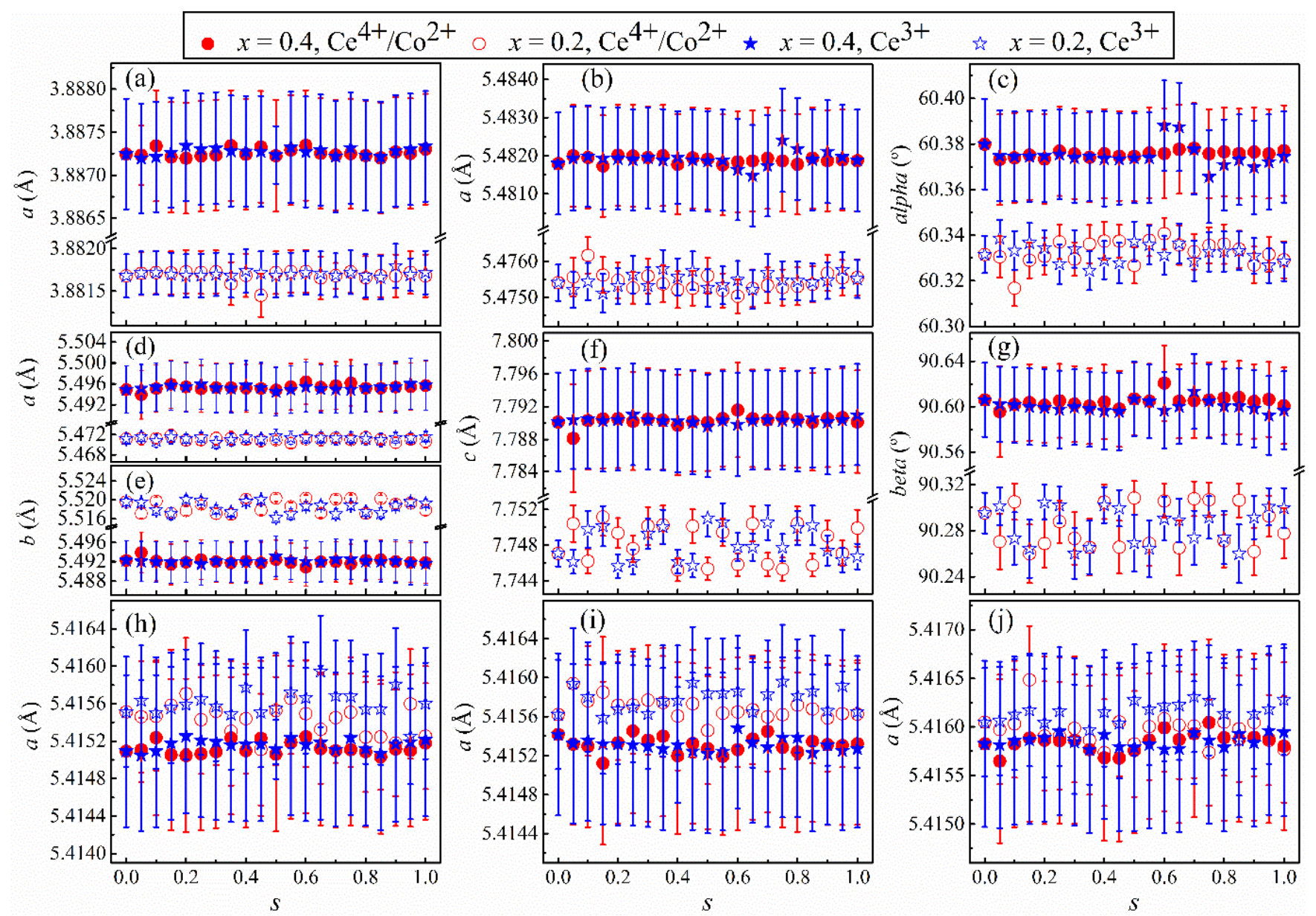

Figure 3. Lattice parameters refined from XRD data for $\mathrm{La}_{1-x} \mathrm{Ce}_{x} \mathrm{CoO}_{3}$ with $x=0.2$ and $x=0.4$, considering two cases of cerium dopants as either $\mathrm{Ce}^{3+}$ or $\mathrm{Ce}^{4+} / \mathrm{Co}^{2+} .(\mathbf{a}-\mathrm{g})$ Lattice parameters of the main phase with a lattice model of (a) cubic, $(\mathbf{b}, \mathbf{c})$ rhombohedral, and $(\mathbf{d}-\mathbf{g})$ monoclinic. $(\mathbf{h}-\mathbf{j})$ Lattice parameters of the secondary phase, $\mathrm{CeO}_{2}$, where (h) the main phase is cubic, (i) the main phase is rhombohedral, and (j) the main phase is monoclinic. 
Table 4. Weight percent and microstructural details of individual phases of $\mathrm{La}_{1-x} \mathrm{Ce}_{x} \mathrm{CoO}_{3}$, as determined from the Rietveld refinement analysis. Numbers in parentheses are statistical errors of the last significant digit (Main = main phase, Second = Secondary phase).

\begin{tabular}{|c|c|c|c|c|c|c|c|}
\hline \multirow{2}{*}{$x$} & \multirow{2}{*}{ Main Phase Lattice Model } & \multicolumn{2}{|c|}{ Weight \% } & \multicolumn{2}{|c|}{ Crystallite Size (Å) } & \multicolumn{2}{|c|}{ Micro-Strain (\%) } \\
\hline & & Main & Second & Main & Second & Main & Second \\
\hline 0.0 & Rhombohedral & $85.5(2)$ & $14.5(2)$ & 1411(39) & $1045(38)$ & $0.160(3)$ & $0.186(7)$ \\
\hline 0.0 & Monoclinic & $85.3(3)$ & $14.7(3)$ & $1386(38)$ & $908(35)$ & $0.160(3)$ & $0.166(6)$ \\
\hline 0.2 & Cubic & $86.5(1)$ & $13.5(1)$ & $228(1)$ & $167(2)$ & $0.278(4)$ & $0.048(1)$ \\
\hline 0.2 & Rhombohedral & $86.4(1)$ & $13.6(1)$ & $236(1)$ & $171(2)$ & $0.181(7)$ & $0.031(2)$ \\
\hline 0.2 & Monoclinic & $86.4(1)$ & $13.6(1)$ & $242(2)$ & $171(2)$ & $0.104(6)$ & $0.039(3)$ \\
\hline 0.4 & Cubic & $43.6(3)$ & $56.4(3)$ & $185(9)$ & 171(5) & $0.17(2)$ & $0.11(2)$ \\
\hline 0.4 & Rhombohedral & $42.7(3)$ & $57.3(3)$ & 211(9) & $171(5)$ & $0.049(8)$ & $0.11(2)$ \\
\hline 0.4 & Monoclinic & $42.8(3)$ & $57.2(3)$ & 211(9) & 171(5) & $0.047(5)$ & $0.16(1)$ \\
\hline
\end{tabular}

Normalized XANES spectra at the Ce $L_{3}$-edge together with the curve fits in Figure 5 show that $\mathrm{Ce}$ of $\mathrm{La}_{1-x} \mathrm{Ce}_{x} \mathrm{CoO}_{3}$ is in a mixed-valence state in both cases of $x$ studied. It is apparent from the spectra the characteristic two-peak structure, the physical origin of which is elucidative in the work of Kotani and colleagues [42]. In the $2 p \rightarrow 5 d$ photo-absorption, a Ce $2 p$ core electron absorbs an incident photon and is excited to the Ce $5 d$ conduction band, leaving behind a core-hole denoted as $2 p_{3 / 2}$. The initial state of the Ce is a superposed state of $c_{0}\left|f^{0}\right\rangle+c_{1}\left|f^{1} L\right\rangle[42,43]$, where $c_{0}$ and $c_{1}$ are real coefficients, and Lindicates a ligand hole resulting from the $\mathrm{O} 2 p \rightarrow$ Ce $4 f$ charge transfer. The final state is a consequence of the interplay of three interactions: the Coulomb attraction between the photo-excited $5 d$ electron $\left(5 d^{*}\right)$ and the core-hole, the Coulomb repulsion between the $4 f$ electron and $5 d^{*}$, and the core-hole attractive potential acting on the $4 f$ electron. The roles of these interactions are to localize the $5 d^{*}$ near the core hole site, split the Ce $5 d$ final state into $2 p_{3 / 2} 4 f^{0} 5 d^{*}$ and $2 p_{3 / 2} 4 f^{1} \underline{L} 5 d^{*}$ configurations, and bring about the $4 f$ electron relaxation in the final state, respectively. Consistent with this description, we decompose each XANES spectrum into a combination of two Gaussian peaks, describing the $5 d$ final states and an arctangent edge jump simulating the transition into continuum states. Dashed lines in Figure 5 illustrate the deconvolution procedure. Peak A represents the Ce tetravalent state with the configuration $2 p_{3 / 2} 4 f^{0} 5 d^{*}$. Peak B depicts the $2 p_{3 / 2} 4 f^{1} \underline{L} 5 d^{*}$ state. Using weighted ratio of the areas under peak $A\left(\mathrm{~A}^{4+}\right)$ and peak $B\left(\mathrm{~A}^{3+}\right)$, we estimate from the formula $3+\left(\mathrm{A}^{4+} /\left(\mathrm{A}^{3+}+\mathrm{A}^{4+}\right)\right)$ the Ce spectroscopic valence of 3.41 and 3.45 for $x=0.2$ and $x=0.4$, respectively. These values are smaller than 3.49 [31] and 3.56 [34], as previously determined for $\mathrm{CeO}_{2}$. Hence, the results of spectroscopic valence obtained here might signify at least two crystallographic, distinct $\mathrm{Ce}$ sites in the $\mathrm{La}_{1-x} \mathrm{Ce}_{x} \mathrm{CoO}_{3}$ structure.

Table 5. Lattice parameters of individual phases of $\mathrm{La}_{1-x} \mathrm{Ce}_{x} \mathrm{CoO}_{3}$ resulting from the Rietveld refinement. Form of dopants: $\mathrm{Ce}^{4+} / \mathrm{Co}^{2+}$. Numbers in parentheses are statistical errors of the last significant digit.

\begin{tabular}{|c|c|c|c|c|c|c|c|}
\hline & \multicolumn{4}{|c|}{ Main Phase } & \multicolumn{3}{|c|}{ Secondary Phase (All Cubic) } \\
\hline & \multirow{2}{*}{ Lattice } & \multirow{2}{*}{$x=0$} & \multirow{2}{*}{$x=0.2$} & \multirow{2}{*}{$x=0.4$} & $x=0$ & $x=0.2$ & $x=0.4$ \\
\hline & & & & & $\mathrm{Co}_{3} \mathrm{O}_{4}$ & $\mathrm{CeO}_{2}$ & $\mathrm{CeO}_{2}$ \\
\hline$a(\AA)$ & Cubic & & $3.8817(2)$ & $3.8873(6)$ & & $5.4154(6)$ & $5.4151(8)$ \\
\hline$a(\AA)$ & Rhombohedral & $5.3855(2)$ & $5.4754(5)$ & $5.482(1)$ & $8.0796(6)$ & $5.4157(6)$ & $5.4153(8)$ \\
\hline$\alpha\left({ }^{\circ}\right)$ & Rhombohedral & $60.727(2)$ & $60.333(8)$ & $60.38(2)$ & & & \\
\hline$a(\AA)$ & Monoclinic & $5.387(2)$ & $5.471(1)$ & $5.495(5)$ & $8.0798(6)$ & $5.4160(5)$ & $5.4158(9)$ \\
\hline$b(\AA)$ & Monoclinic & $5.443(3)$ & $5.5187(9)$ & $5.492(4)$ & & & \\
\hline$c(\AA)$ & Monoclinic & $7.657(4)$ & $7.748(2)$ & $7.790(6)$ & & & \\
\hline$\beta\left(^{\circ}\right)$ & Monoclinic & $90.91(3)$ & $90.28(2)$ & $90.60(3)$ & & & \\
\hline
\end{tabular}




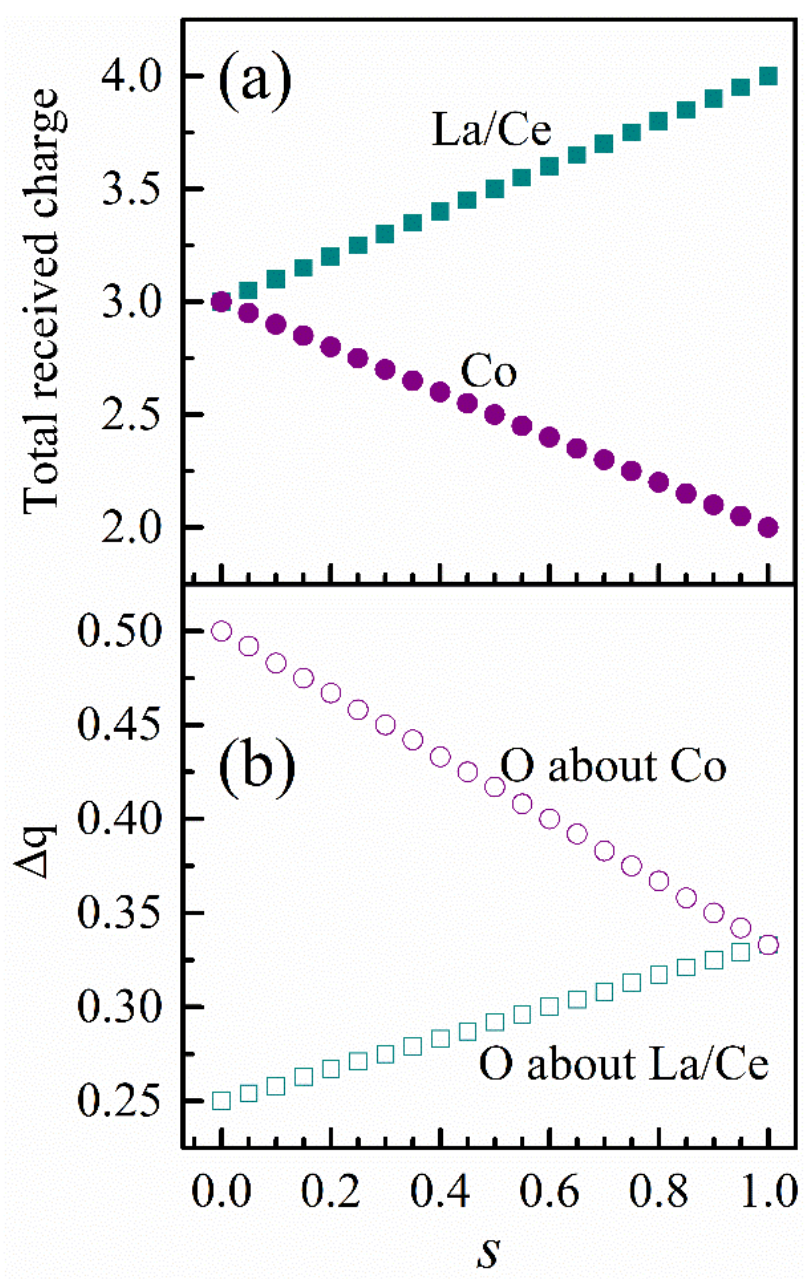

Figure 4. (a) Total charge received by La/Ce and Co and (b) fraction of charge $(\triangle \mathrm{q})$ received by each O-coordination about $\mathrm{La} / \mathrm{Ce}$ and $\mathrm{Co}$ as a function of $s$, the fraction of cerium dopants in $\mathrm{La}_{1-s} \mathrm{Ce}_{s} \mathrm{CoO}_{3}$, which is the main phase of $\mathrm{La}_{1-x} \mathrm{Ce}_{x} \mathrm{CoO}_{3}$. The calculations use the structural parameters obtained from the Rietveld refinement analysis, considering the main lattice as a cubic lattice.

Figure 6 shows XANES data at the $\mathrm{La}_{2}$-edge for $\mathrm{La}_{1-x} \mathrm{Ce}_{x} \mathrm{CoO}_{3}$. The spectrum of the pristine LCO reveals a sharp white line and two post-edge bulging features. These structures indicate holes in the La $5 d$-band, $\mathrm{O} 2 p$-La $5 d$ hybridization states, and possibly part of EXASF, respectively. It is clearly visible that the white line becomes enhanced with increasing Ce content, whereas the post-edge structure analogous to the bulge in the middle of the $x=0$ spectrum takes a flat shape in the cases $x=0.2$ and $x=0.4$. These changes establish direct evidence that the La $5 d$-band of the pristine LCO is in a partially filled state and eventually turns into a less occupied state when subject to the Ce addition. This finding on the occupancy of the La $5 d$-band seems to be unexpected, because the La-O bond is commonly anticipated to be pure ionic, owing to a difference greater than 2.0 between the Pauling's electronegativity of $\mathrm{La}$ (1.1) and that of $\mathrm{O}$ (3.44). There is, in fact, a differentiation of the $\mathrm{La}-\mathrm{O}$ bond length in LCO; $\mathrm{La}-\mathrm{O}$ bonds with short enough bond lengths have some covalent character, as is revealed in the discussion that follows. 


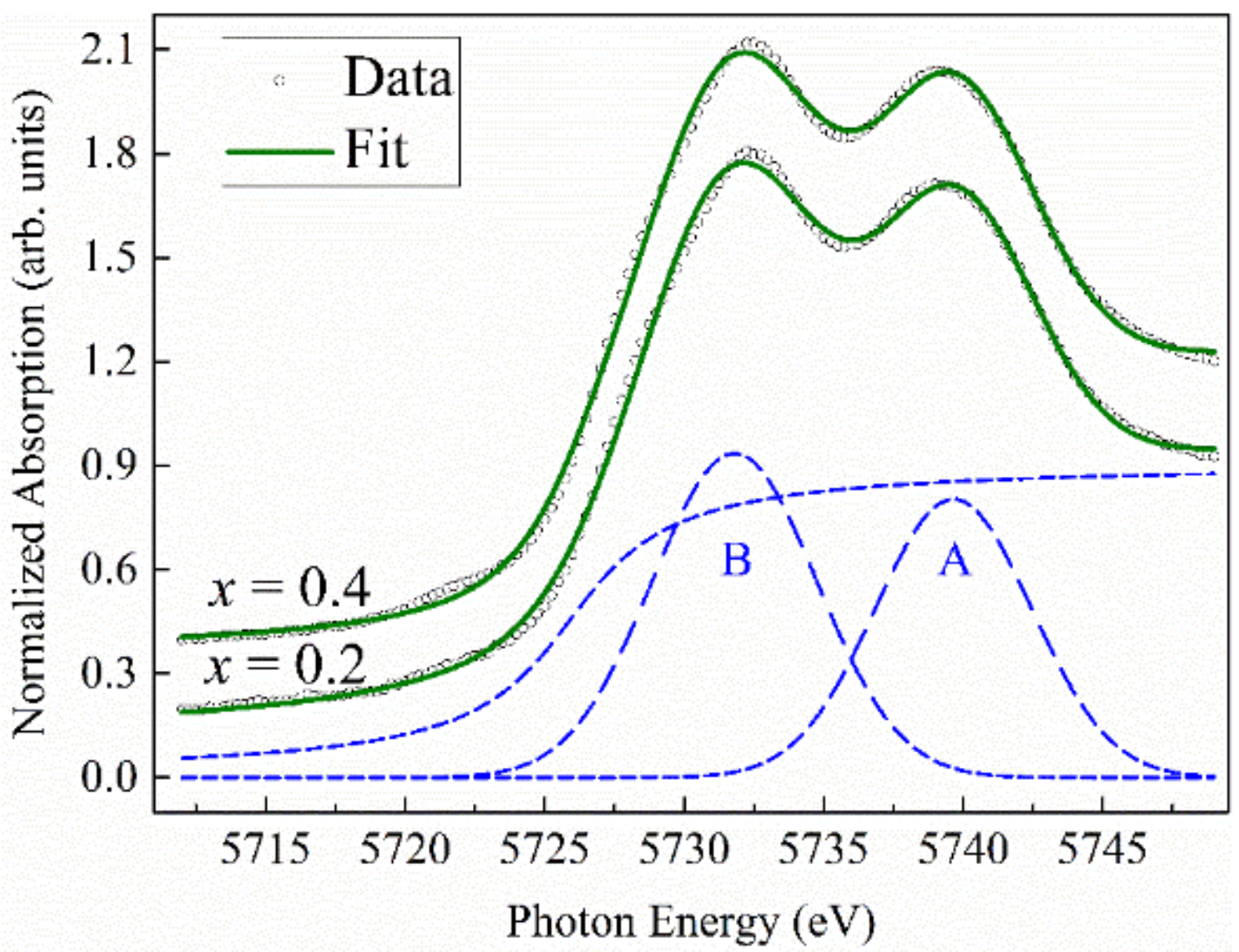

Figure 5. XANES spectra at the $\mathrm{Ce} L_{3}$ edge of $\mathrm{La}_{1-x} \mathrm{Ce}_{x} \mathrm{CoO}_{3}$, with (A) $x=0.2$ and (B) $x=0.4$, and results of least-squares-fit analyses. The dashed lines indicate the fitting procedure.

Table 6. Details of local coordination for La and Co of the main phase, as a result of the Rietveld refinement analysis. Numbers in parentheses are statistical errors of the last significant digit.

\begin{tabular}{|c|c|c|c|c|}
\hline$x$ & $\begin{array}{l}\text { Main Phase Lattice } \\
\text { Model }\end{array}$ & $\begin{array}{l}\text { Coordination and } \\
\text { Multiplicity }\end{array}$ & $\begin{array}{l}\text { Distance } \\
\text { (§) }\end{array}$ & $\begin{array}{c}\text { Fraction of the Charge Received } \\
\text { by Each O-Coordination }\end{array}$ \\
\hline \multirow{5}{*}{0} & \multirow{5}{*}{ Rhombohedral } & $\mathrm{La}-\mathrm{O} \times 3$ & $2.4384(1)$ & 0.447 \\
\hline & & $\mathrm{La}-\mathrm{O} \times 3$ & $2.7074(1)$ & 0.240 \\
\hline & & $\mathrm{La}-\mathrm{O} \times 3$ & $2.7079(1)$ & 0.239 \\
\hline & & $\mathrm{La}-\mathrm{O} \times 3$ & $3.0062(1)$ & 0.074 \\
\hline & & $\mathrm{Co}-\mathrm{O} \times 6$ & $1.93510(8)$ & 0.500 \\
\hline \multirow{10}{*}{0} & \multirow{10}{*}{ Monoclinic } & $\mathrm{La}-\mathrm{O} \times 1$ & $2.411(1)$ & 0.472 \\
\hline & & $\mathrm{La}-\mathrm{O} \times 2$ & $2.4549(9)$ & 0.437 \\
\hline & & $\mathrm{La}-\mathrm{O} \times 2$ & $2.662(1)$ & 0.272 \\
\hline & & $\mathrm{La}-\mathrm{O} \times 2$ & 2.711(1) & 0.236 \\
\hline & & $\mathrm{La}-\mathrm{O} \times 2$ & $2.750(1)$ & 0.209 \\
\hline & & $\mathrm{La}-\mathrm{O} \times 2$ & $2.991(1)$ & 0.078 \\
\hline & & $\mathrm{La}-\mathrm{O} \times 1$ & $3.032(2)$ & 0.064 \\
\hline & & $\mathrm{Co}-\mathrm{O} \times 2$ & $1.8988(6)$ & 0.558 \\
\hline & & $\mathrm{Co}-\mathrm{O} \times 2$ & $1.939(1)$ & 0.494 \\
\hline & & $\mathrm{Co}-\mathrm{O} \times 2$ & $1.9688(8)$ & 0.448 \\
\hline \multirow{2}{*}{0.2} & \multirow{2}{*}{ Cubic } & $\mathrm{La}-\mathrm{O} \times 12$ & $2.7448(3)$ & 0.250 to 0.333 (plotted in Figure 4 ) \\
\hline & & $\mathrm{Co}-\mathrm{O} \times 6$ & $1.9409(2)$ & 0.500 to 0.333 (plotted in Figure 4) \\
\hline \multirow{2}{*}{0.4} & \multirow{2}{*}{ Cubic } & $\mathrm{La}-\mathrm{O} \times 12$ & $2.7487(5)$ & 0.250 to 0.333 (plotted in Figure 4 ) \\
\hline & & $\mathrm{Co}-\mathrm{O} \times 6$ & $1.9436(4)$ & 0.500 to 0.333 (plotted in Figure 4 ) \\
\hline
\end{tabular}




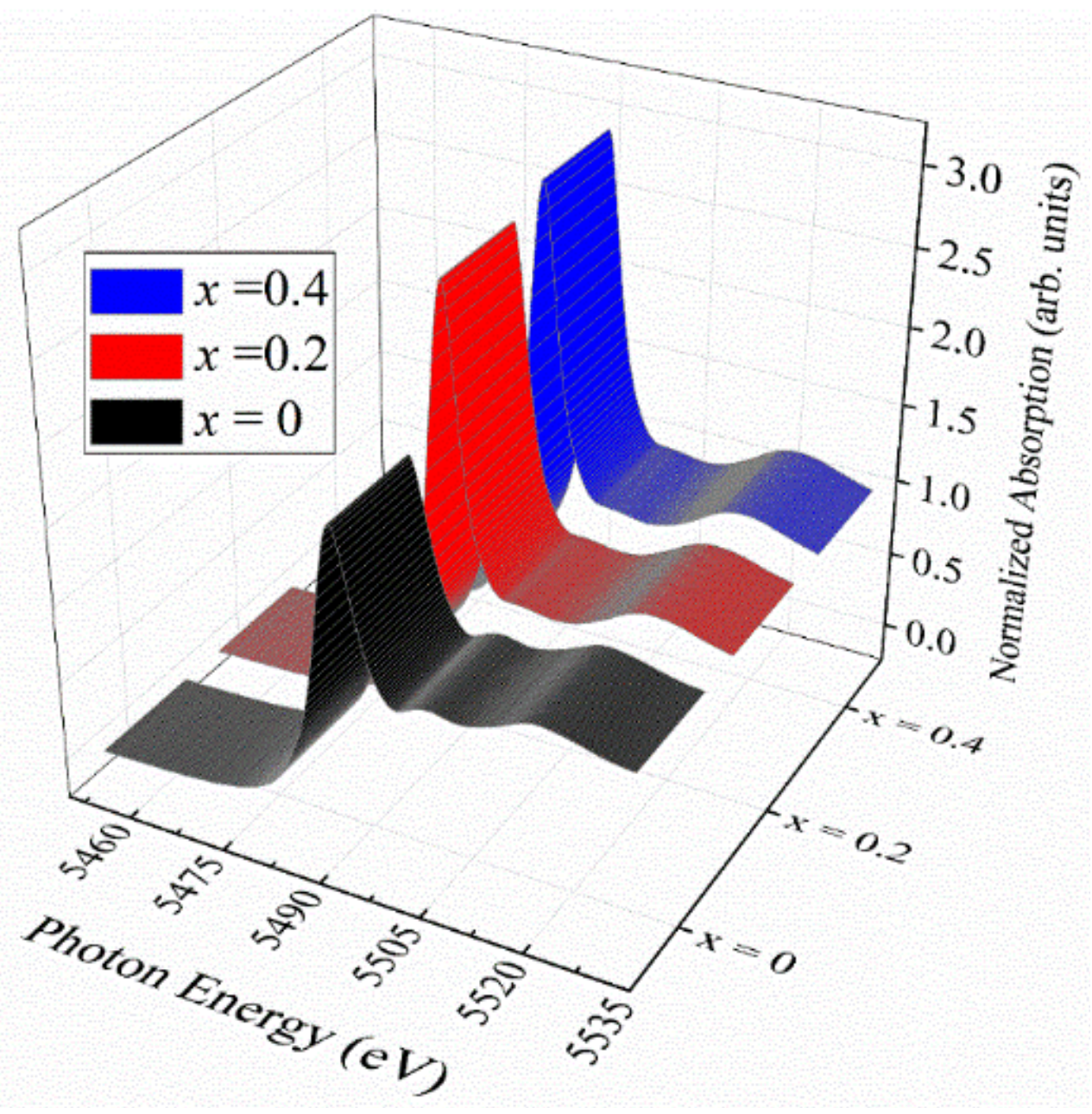

Figure 6. XANES spectra at the $\mathrm{La} L_{3}$-edge of $\mathrm{La}_{1-x} \mathrm{Ce}_{x} \mathrm{CoO}_{3}$, where $x=0,0.2$, and 0.4 .

Figure 7 illustrates the local coordination geometry around the La atoms associated with different primitive cells of different lattice models for the main phase of $\mathrm{La}_{1-x} \mathrm{Ce}_{x} \mathrm{CoO}_{3}$. The La atom in either the rhombohedral model or monoclinic model for $x=0$ is surrounded by $9 \mathrm{O}$ atoms, as opposed to 12 in a representative of cubic model for $x=0.2$ and $x=0.4$. This illustration is consistent with the calculation of "effective" coordination number (ECN), using the output from the Rietveld refinement analysis in the present work. The results give the ECN as 8.95 and 8.77 for the rhombohedral model and monoclinic model, respectively, and 12 for the cubic model. More specifically, Table 6 lists for each lattice model all $12 \mathrm{La}-\mathrm{O}$ distances and the fraction of charge received by each coordinating $\mathrm{O}$ atom. Regarding the rhombohedral model, there is a threefold degenerate La-O distance of $3.0062 \AA$, of which each $\mathrm{O}$ receives only 0.074 of the charge. In the case of the monoclinic model, there are also three such long La-O distances. They are, however, split into a twofold degenerate distance of $2.991 \AA$ and a sole distance of $3.032 \AA$. The $\mathrm{O}$ atoms corresponding to these distances gain unsubstantial charge fractions as 0.078 and 0.064 , respectively. For this reason, the number of effectively coordinate La-O bonds remains $\sim 9$ for both the rhombohedral and monoclinic models. In contrast, $\mathrm{La}$ is bonded to twelve equivalent $\mathrm{O}$ in a 12-coordinate geometry in the cubic model, where all La-O bond lengths are $\sim 2.74 \AA$. This distinction in the La local structure elucidates the observable changes in the La XANES data in Figure 6.

It is necessary to scrutinize the physical nature of interatomic interactions to gain more evidence to support our findings from the La $L_{3}$-edge XANES observations. Each of Figure $8 \mathrm{a}-\mathrm{c}$ shows a $2 \times 2 \times 2$ supercell of different lattice models for the main phase of $\mathrm{La}_{1-x} \mathrm{Ce}_{x} \mathrm{CoO}_{3}$ along the lattice vector $a$. A solid (blue) line therein marks a rhombohedral (011) plane, a monoclinic (0-11) plane, and a cubic (001) plane. In Figure 8d-f, pictorial 
details of these planes depict the short $(2.4 \AA)$, intermediate $(2.7 \AA)$, and long $(3.0 \AA)$ La-O distances. These structural descriptions serve as the basis for further considerations of the experimental electron density and the electronic energy distribution shown in Figure 9a-f, respectively. Figure 9a explicitly shows an uneven electronic distribution in the rhombohedral (011) plane. Regarding each La atom, which coordinates with $4 \mathrm{O}$ atoms, the interatomic region of a short $\mathrm{La}-\mathrm{O}$ distance has a higher electron density than that of the three longer $\mathrm{La}-\mathrm{O}$ distances. Correspondingly, Figure $9 \mathrm{~d}$ shows the electronic energy maximally negative in the midway region of the short $\mathrm{La}-\mathrm{O}$ bond, which unequivocally indicates a shared-type atomic interaction. The observations found here profusely resemble results from inspections for the monoclinic (0-11) plane in Figure 9b,e. In contrast, the electron density distribution shown in Figure $9 \mathrm{c}$ is uniform for all $\mathrm{La}-\mathrm{O}$ bonds in the cubic (001) plane. Furthermore, according to the electron energy distribution in Figure 9f, each La atom in the cubic (001) plane participates in four closed-shell interactions with adjacent $\mathrm{O}$ atoms. Overall, these facts infer that some $\mathrm{La}-\mathrm{O}$ bonding states of the pristine $\mathrm{LCO}$ have a covalent bond nature in both rhombohedral and monoclinic lattice models and tend to favor a change towards being nearly pure ionic in cubic Ce-doped LCO.

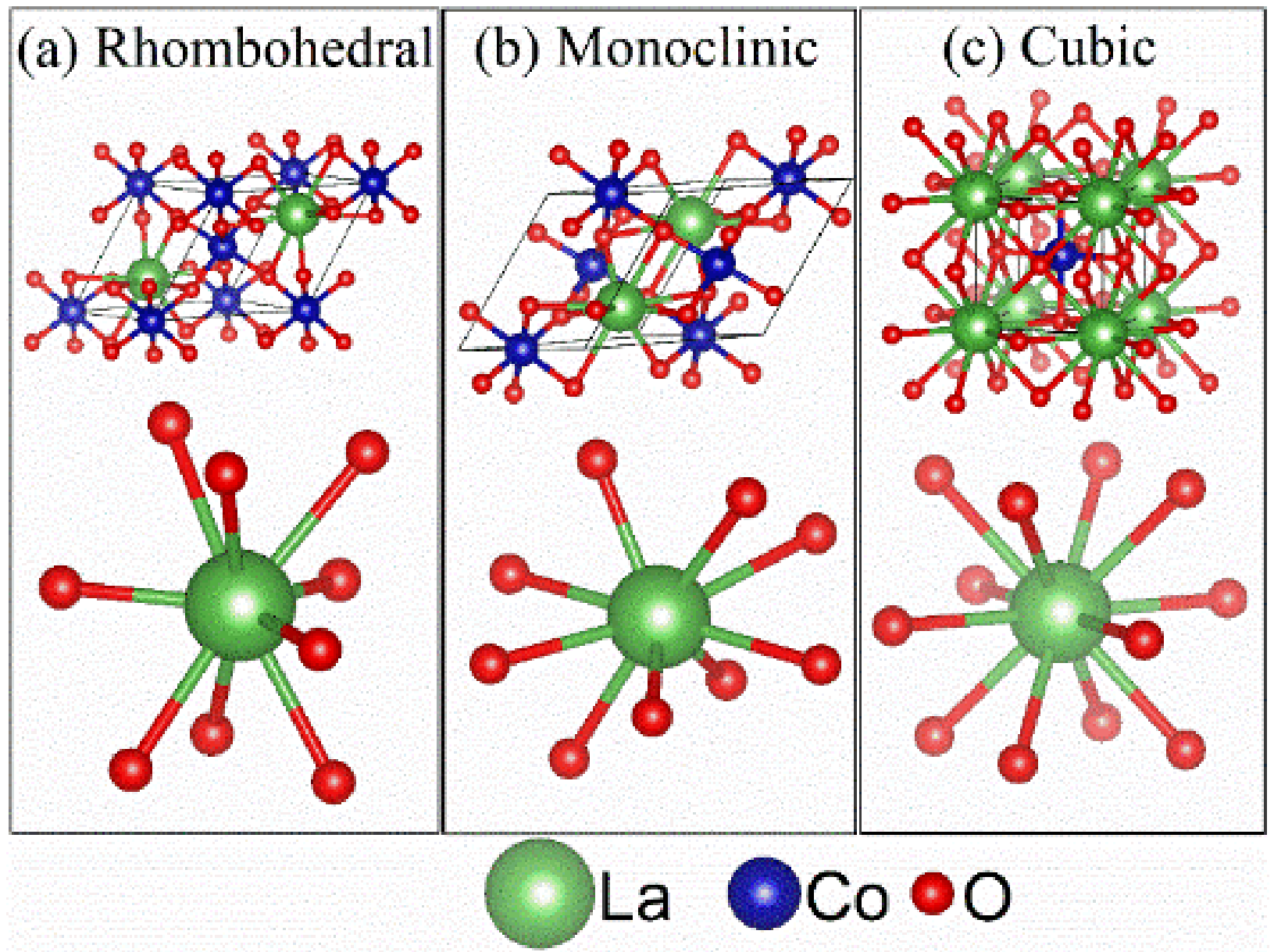

Figure 7. Schematic of the primitive cell of different models for the main phase of $\mathrm{La}_{1-x} \mathrm{Ce}_{x} \mathrm{CoO}_{3}$ as (a) rhombohedral, (b) monoclinic, and (c) cubic, and local coordination geometry around La atoms showing the difference in the effective coordination number. 


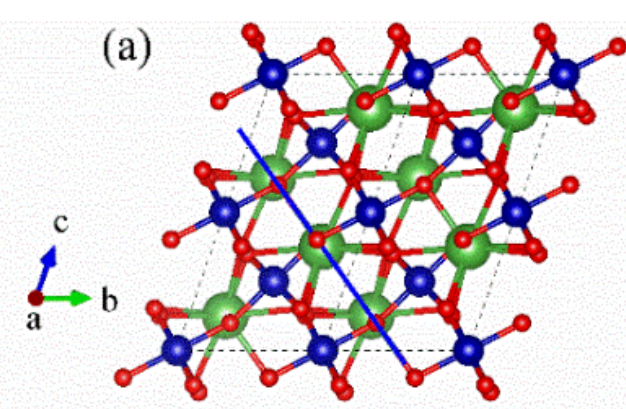

(d) $\left(\begin{array}{lll}0 & 1 & 1\end{array}\right)$

Rhombohedral

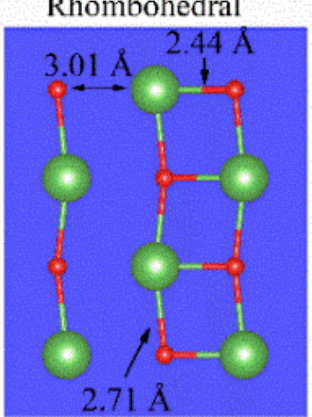

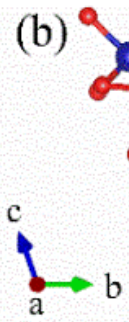

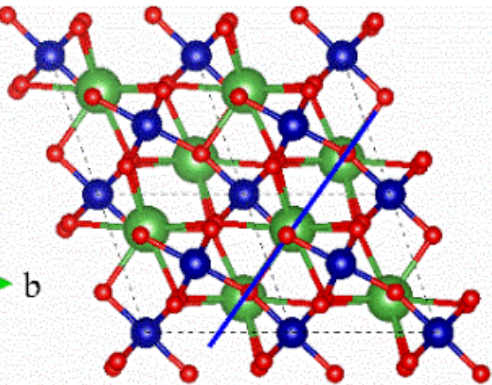

Monoclinic

(e) $(0-11)$

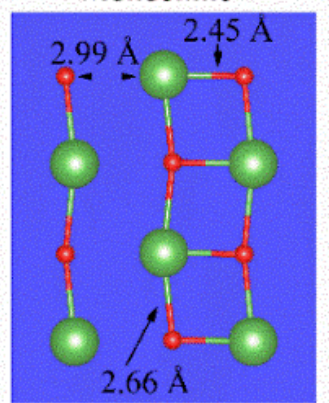

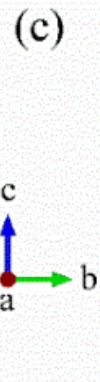

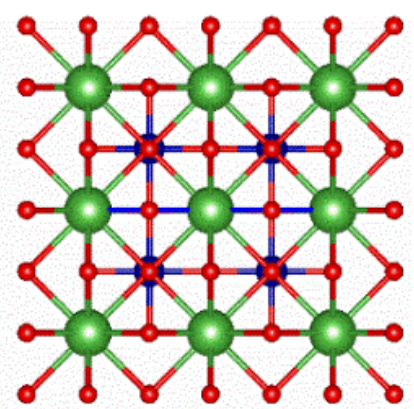

Cubic

(f) $\left(\begin{array}{lll}0 & 0 & 1\end{array}\right)$

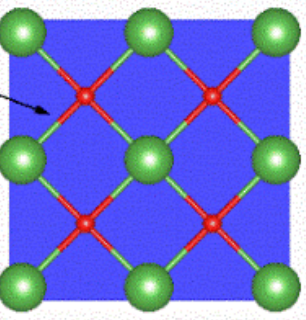

$\mathrm{La} \odot \mathrm{Co} \odot \mathrm{O}$

Figure 8. A $2 \times 2 \times 2$ supercell of different models for the main phase of $\mathrm{La}_{1-x} \mathrm{Ce}_{x} \mathrm{CoO}_{3}$ along the lattice vector $a$ : (a) rhombohedral, (b) monoclinic, and (c) cubic. A solid blue line marks (a) a (011) plane of the rhombohedral lattice, (b) a (0-11) plane of the monoclinic lattice, and (c) a (001) plane of the cubic lattice. $(\mathbf{d}-\mathbf{f})$ Details of the corresponding plane marked in $(\mathbf{a}-\mathbf{c})$, respectively.

(a)

1.0
0.9
0.8
0.7
0.6
0.5
0.4
0.3
0.2
0.1
$0.0 a_{0}^{-3}$

0.0

$-0.002$

$-0.004$

$-0.006$

$-0.008$

$-0.01$

$-0.012$

$-0.014$

$-0.016$

-0.018
$-0.02 E_{\mathrm{h}} a_{0}^{-3}$

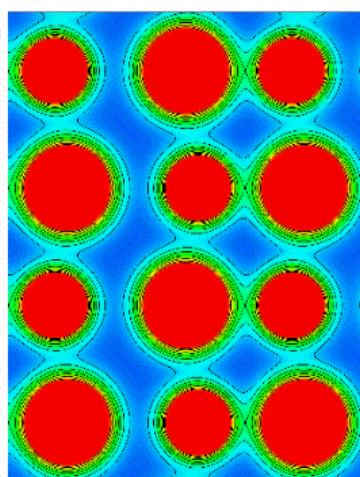

(b)

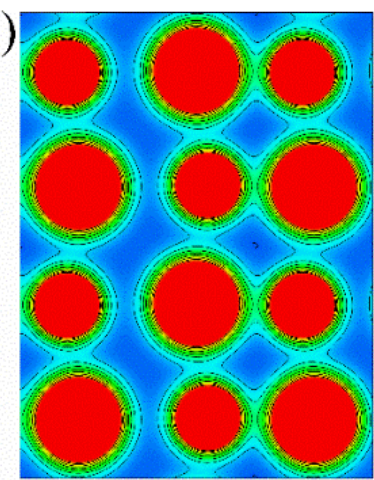

(d)

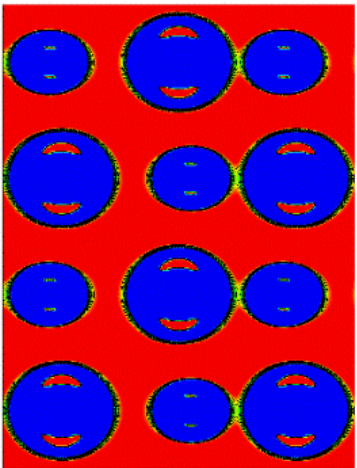

(e)

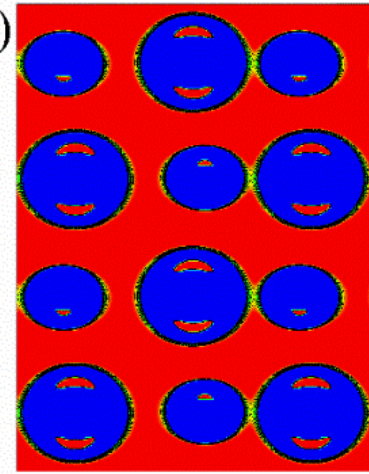

(c)

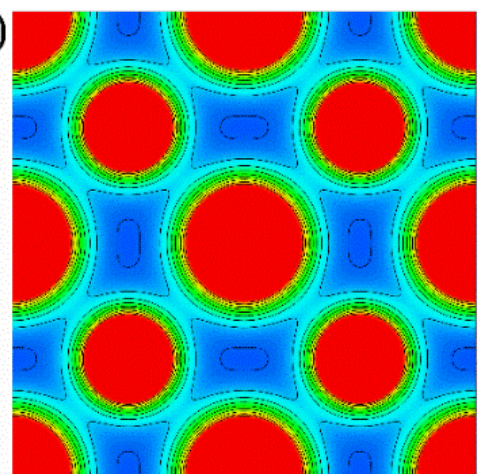

(f)

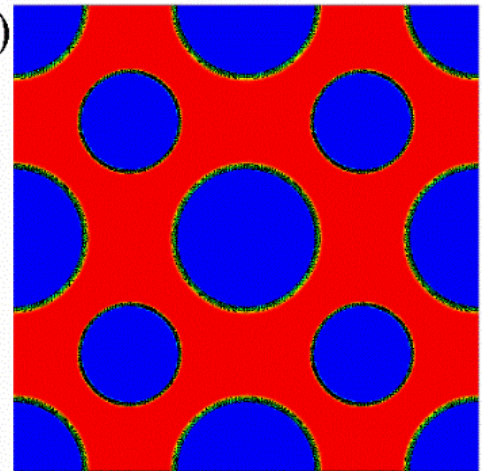

Figure 9. (a-c) Electron-density distribution on a plane in the main lattice of $\mathrm{La}_{1-x} \mathrm{Ce}_{x} \mathrm{CoO}_{3}$ of different models. (a) a (011) plane of the rhombohedral lattice, (b) a (011) plane of the monoclinic lattice, and (c) a (011) plane of the cubic lattice. Contours are plotted up to $1.0 a_{0}{ }^{-3}$, with an interval of $0.1 a_{0}{ }^{-3} \cdot a_{0}=0.529177211 \AA$ ( $a_{0}$ : Bohr radius). (d-f) Electronic energy map of the corresponding plane in $(\mathbf{a}-\mathbf{c})$. Contours are plotted down to $-0.02 E_{\mathrm{h}} a_{0}{ }^{-3}$, with an interval of $-0.002 E_{\mathrm{h}} a_{0}{ }^{-3}$. $E \mathrm{~h}=4.3597443 \times 10^{-18} \mathrm{~J}($ Eh: Hartree $)$. 
Figure 10 shows the normalized Co K-edge XAS data measured on the $\mathrm{La}_{1-x} \mathrm{Ce}_{x} \mathrm{CoO}_{3}$ samples and extracted $k^{2}$-weighted $\chi(k)$ data. All the EXAFS fits for $x=0.2$ using different values of $s$ resulted in intuitively identical curves. The same situation holds for $x=0.4$. Therefore, we show only a representative graph of $s=0.25$ for each case of $x$ when comparing the Fourier-transformed EXAFS signals in Figure 11. It is obvious therein that the theoretical fitting curves match closely with both the magnitude and the real part of the real-space EXAFS data. Moreover, fitted parameters from these fits have adopted reasonable values, as listed in Tables 7-9. Minute changes of all the radial distances, except for the value $0.16 \AA$ of the path @La1.1@ in the case $x=0$, justify the Rietveld refinement analysis and the EXAFS models used.
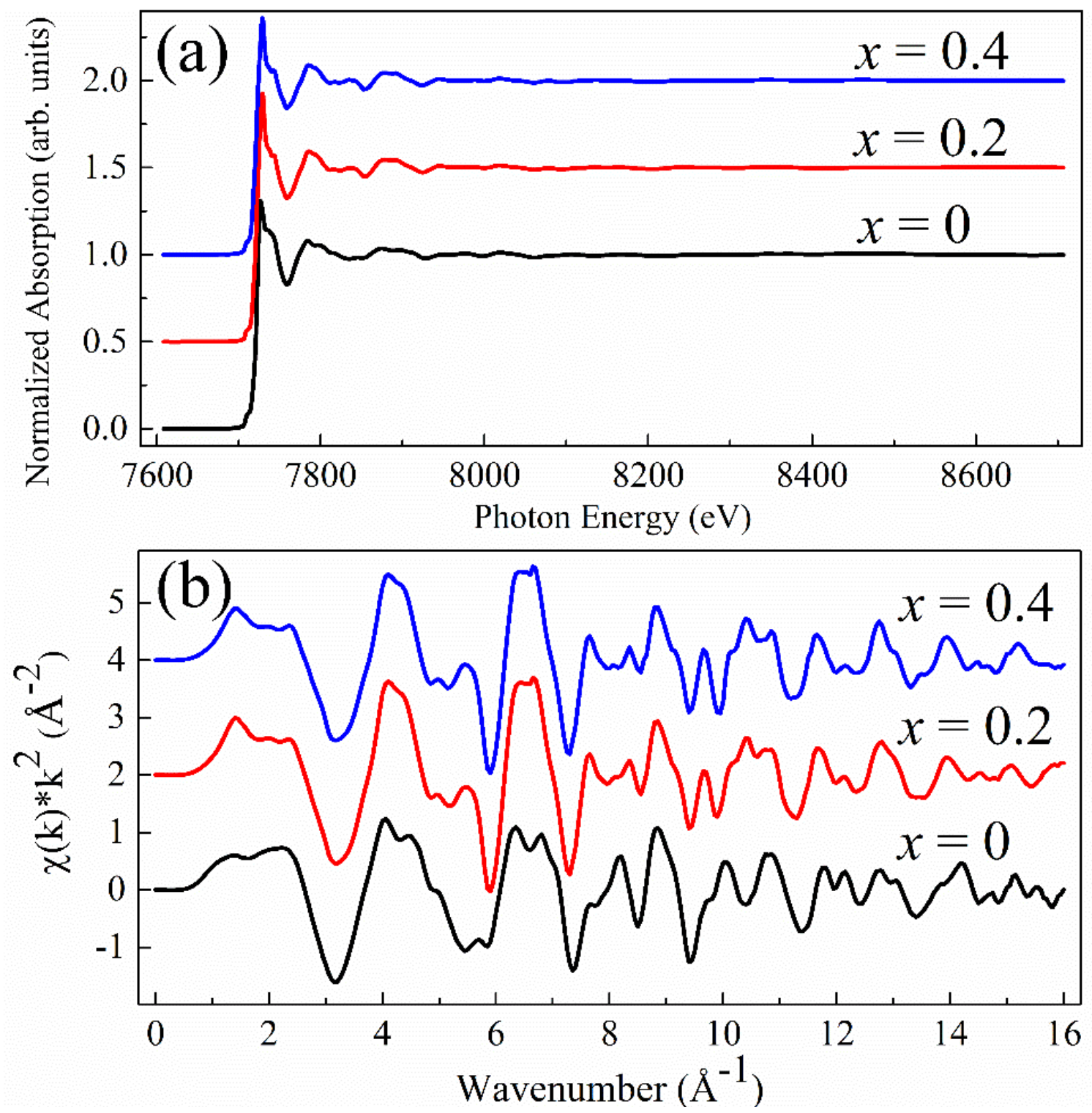

Figure 10. (a) Normalized absorption data measured at the $\mathrm{Co} K$-edge of $\mathrm{La}_{1-x} \mathrm{Ce}_{x} \mathrm{CoO}_{3}$, where $x=0$, 0.2 , and 0.4. (b) Extracted $k^{2}$-weighted $\chi(k)$ data.

The resulting sigma square terms $\sigma^{2}$, accounting for the mean square variation in path lengths, require some discussion. The $\sigma^{2}$ value of the path @O1.1@ is smaller in the case of $x=0$ than in the cases $x=0.2$ and 0.4 . Such an attribute depends directly on a difference of one La-O bonding between the rhombohedral lattice and the cubic lattice assumed for the main scattering phase. If LCO crystallizes in the rhombohedral $R-3 c$ : $R$ space group, $\mathrm{O}$ is bonded in a 5-coordinate geometry to three equivalent La and two equivalent 
Co atoms. Considering Ce-doped LCO in the cubic Pm-3m symmetry, $\mathrm{O}$ is bonded in a distorted linear geometry to four equivalent $\mathrm{La}$ and two equivalent $\mathrm{Co}$ atoms. To that end, the relative displacement $\mathrm{Co} \rightarrow \mathrm{O} 1.1$ in the cubic lattice possesses more disorder than that in the rhombohedral lattice. In addition, the $\sigma^{2}$ value of the path @O1.1@ is greater than that of the path@O_SS@ in any case of $x$. This property also derives from the local coordination geometry. Regarding $\mathrm{Co}_{3} \mathrm{O}_{4}$ in the cubic $F d-3 m$ symmetry, $\mathrm{O}$ is bonded in a distorted trigonal pyramidal geometry to four Co atoms. Hence, the two scattering phases under consideration differ in both metal-oxygen bonding numbers and atomic coordination types, and the number of metal-oxygen bonding prevails in influencing the disorder of the scattering paths.
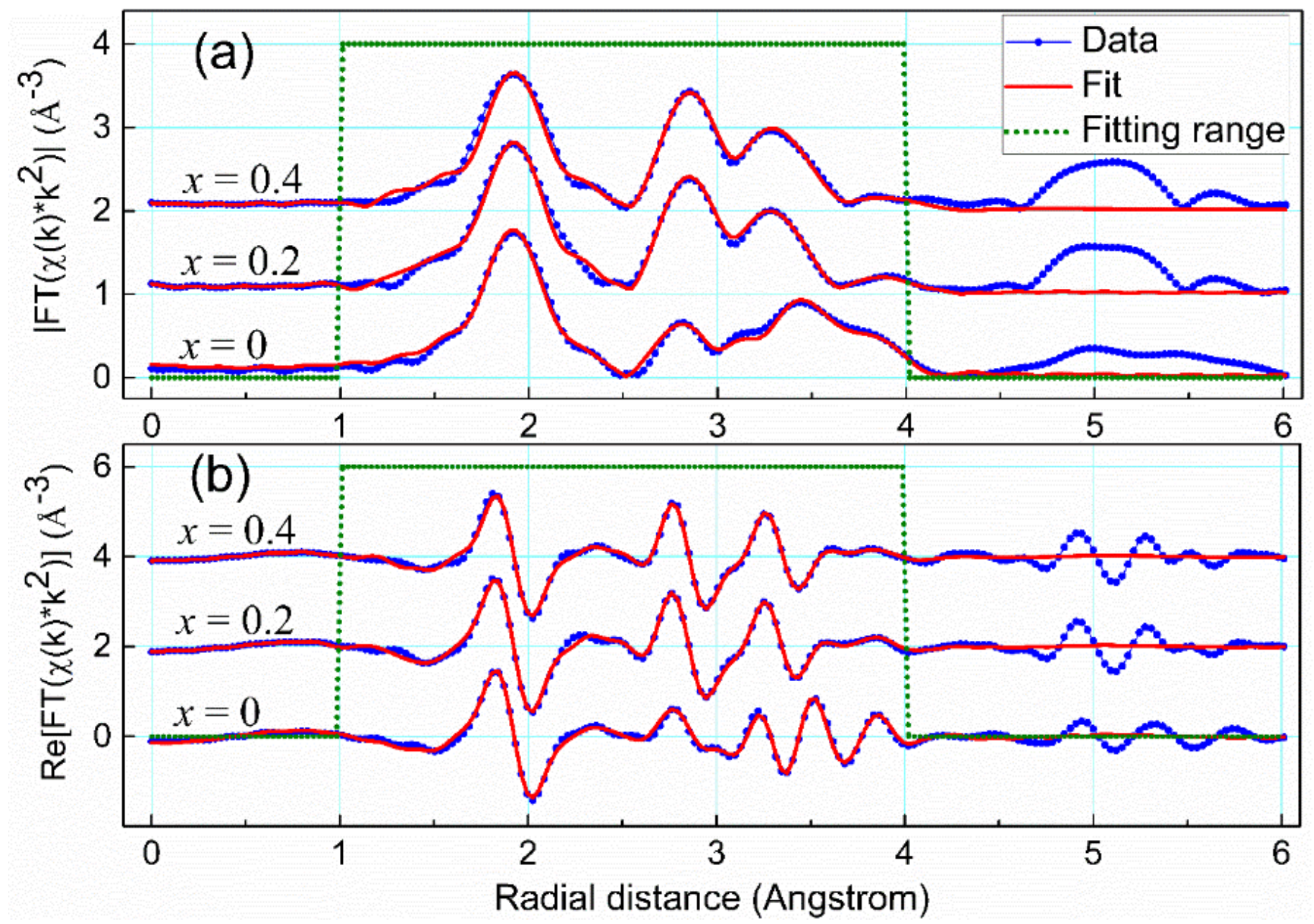

Figure 11. Data and fit for EXAFS data of $\mathrm{La}_{1-x} \mathrm{Ce}_{x} \mathrm{CoO}_{3}$ with $x=0,0.2$, and 0.4: (a) magnitude and (b) real part of Fourier transform from the corresponding $k^{2}$-weighted $\chi(k)$ data. 
Table 7. EXAFS fit values for $x=0 . R$-factor $=0.0145 . S_{0}^{2}=1$ (Rhombo $=$ Rhombohedral).

\begin{tabular}{|c|c|c|c|c|c|}
\hline Scattering Phase & Scattering Path & $\sigma_{j i}^{2}\left(\AA^{2}\right)$ & $\Delta E_{0}^{j}(\mathrm{eV})$ & $\Delta R_{j}(\AA ̊)$ & $R_{j i}(\AA)$ \\
\hline Rhombo $\mathrm{LaCoO}_{3}$ & @ O1.1 @ & 0.0120 & 0.3 & -0.049 & 1.887 \\
\hline Rhombo $\mathrm{LaCoO}_{3}$ & @ La1.1@ & 0.0037 & 0.3 & 0.160 & 3.440 \\
\hline Rhombo $\mathrm{LaCoO}_{3}$ & @ La1.2@ & 0.0037 & 0.3 & 0.005 & 3.333 \\
\hline Rhombo $\mathrm{LaCoO}_{3}$ & @ Co1.1@ & 0.0072 & 0.3 & -0.048 & 3.781 \\
\hline Rhombo $\mathrm{LaCoO}_{3}$ & @ O1.1Co1.1@ @ & 0.0072 & 0.3 & -0.025 & 3.825 \\
\hline Rhombo $\mathrm{LaCoO}_{3}$ & @ O1.1Co1.1 O1.1@ & 0.0072 & 0.3 & -0.048 & 3.823 \\
\hline $\mathrm{Co}_{3} \mathrm{O}_{4}$ & @O_SS@ & 0.0020 & -5.7 & -0.006 & 1.918 \\
\hline $\mathrm{Co}_{3} \mathrm{O}_{4}$ & @Co_SS1 @ & 0.0080 & -5.7 & -0.008 & 2.848 \\
\hline $\mathrm{Co}_{3} \mathrm{O}_{4}$ & @ Co_SS2 @ & 0.0296 & -5.7 & -0.010 & 3.340 \\
\hline
\end{tabular}

Table 8. EXAFS fit values for $x=0.2, s=0.25 . R$-factor $=0.0096 . S_{0}^{2}=1$.

\begin{tabular}{|c|c|c|c|c|c|}
\hline Scattering Phase & Scattering Path & $\sigma_{j i}^{2}\left(\AA^{2}\right)$ & $\Delta E_{0}^{j}(\mathrm{eV})$ & $\Delta R_{j}(\AA ̊)$ & $R_{j i}(\AA)$ \\
\hline Cubic $\mathrm{La}_{1-s} \mathrm{Ce}_{5} \mathrm{CoO}_{3}$ & @ O1.1@ & 0.0184 & 0.5 & -0.039 & 1.902 \\
\hline Cubic $\mathrm{La}_{1-s} \mathrm{Ce}_{s} \mathrm{CoO}_{3}$ & @ La1.1@ & 0.0119 & 0.5 & -0.067 & 3.295 \\
\hline Cubic $\mathrm{La}_{1-s} \mathrm{Ce}_{s} \mathrm{CoO}_{3}$ & @ Ce1.1@ & 0.0119 & 0.5 & -0.067 & 3.295 \\
\hline Cubic $\mathrm{La}_{1-s} \mathrm{Ce}_{s} \mathrm{CoO}_{3}$ & @ Co1.1@ & 0.0178 & 0.5 & -0.077 & 3.804 \\
\hline Cubic $\mathrm{La}_{1-s} \mathrm{Ce}_{S} \mathrm{CoO}_{3}$ & @ 01.1Co1.1@ & 0.0178 & 0.5 & -0.077 & 3.804 \\
\hline Cubic $\mathrm{La}_{1-s} \mathrm{Ce}_{5} \mathrm{CoO}_{3}$ & @ O1.1Co1.1O1.1@ & 0.0178 & 0.5 & -0.077 & 3.804 \\
\hline $\mathrm{Co}_{3} \mathrm{O}_{4}$ & @ O_SS@ & 0.0022 & -1.5 & -0.003 & 1.921 \\
\hline $\mathrm{Co}_{3} \mathrm{O}_{4}$ & @ Co_SS1 @ & 0.0037 & -1.5 & -0.004 & 2.853 \\
\hline $\mathrm{Co}_{3} \mathrm{O}_{4}$ & @ Co_SS2 @ & 0.0052 & -1.5 & -0.005 & 3.345 \\
\hline
\end{tabular}

Table 9. EXAFS fit values for $x=0.4, s=0.375 . R$-factor $=0.0113 . S_{0}^{2}=1$.

\begin{tabular}{|c|c|c|c|c|c|}
\hline Scattering Phase & Scattering Path & $\sigma_{j i}^{2}\left(\AA^{2}\right)$ & $\Delta E_{0}^{j}(\mathrm{eV})$ & $\Delta R_{j}(\AA)$ & $R_{j i}(\AA)$ \\
\hline Cubic $\mathrm{La}_{1-s} \mathrm{Ce}_{s} \mathrm{CoO}_{3}$ & @ O1.1@ & 0.0291 & 0.5 & -0.040 & 1.901 \\
\hline Cubic $\mathrm{La}_{1-s} \mathrm{Ce}_{s} \mathrm{CoO}_{3}$ & @ La1.1@ & 0.0145 & 0.5 & -0.070 & 3.292 \\
\hline Cubic $\mathrm{La}_{1-s} \mathrm{Ce}_{s} \mathrm{CoO}_{3}$ & @ Ce1.1@ & 0.0145 & 0.5 & -0.070 & 3.292 \\
\hline Cubic $\mathrm{La}_{1-s} \mathrm{Ce}_{s} \mathrm{CoO}_{3}$ & @ Co1.1@ & 0.0202 & 0.5 & -0.081 & 3.801 \\
\hline Cubic La ${ }_{1-s} \mathrm{Ce}_{s} \mathrm{CoO}_{3}$ & @ O1.1Co1.1@ & 0.0202 & 0.5 & -0.081 & 3.801 \\
\hline Cubic $\mathrm{La}_{1-s} \mathrm{Ce}_{s} \mathrm{CoO}_{3}$ & @ O1.1Co1.1O1.1@ & 0.0202 & 0.5 & -0.081 & 3.801 \\
\hline $\mathrm{Co}_{3} \mathrm{O}_{4}$ & @ O_SS@ & 0.0022 & -0.9 & 0.000 & 1.924 \\
\hline $\mathrm{Co}_{3} \mathrm{O}_{4}$ & @ Co_SS1 @ & 0.0035 & -0.9 & 0.001 & 2.857 \\
\hline $\mathrm{Co}_{3} \mathrm{O}_{4}$ & @ Co_SS2 @ & 0.0053 & -0.9 & 0.001 & 3.350 \\
\hline
\end{tabular}

In addition, regarding the main scattering phase in each case of $x$, the $\sigma^{2}$ value is higher for the path@O1.1@ than other scattering paths, reflecting a reversal dependence of $\sigma^{2}$ on the atomic number of the scattering atom. A similar trend is observable for the $\mathrm{Co}_{3} \mathrm{O}_{4}$-like phase. In general, $\sigma^{2}$ increases with increasing radial distance. In particular, Table 7 shows a $\sigma^{2}$ value as high as $0.0296 \AA^{2}$ for the scattering path @Co_SS2@, whereas the corresponding values in Tables 8 and 9 are $0.0052 \AA^{2}$ and $0.0053 \AA^{2}$, respectively. This seems to indicate that the $\mathrm{Co}_{3} \mathrm{O}_{4}$-like phase is only well-ordered in a shorter range for $x=0$ than for $x=0.2$ and $x=0.4$. It is worth reminding that $\mathrm{Co}_{3} \mathrm{O}_{4}$ crystallites are noticeable from the XRD pattern of the case $x=0$ and missing for $x=0.2$ and $x=0.4$. We thus attribute the difference herein to the degrees of freedom in the fits, i.e., the model with the cubic main lattice has more degrees of freedom than the model with the rhombohedral main lattice.

Furthermore, Figure 12a-f present the full particulars of $R$-factor, $\triangle \mathrm{E}_{0}$, radial distance, and $\sigma^{2}$ as a function of $s$ for $x=0.2$ and $x=0.4$. All the $R$-factors less than 0.02 and the $\triangle \mathrm{E}_{0}$ much less than $10 \mathrm{eV}$ are strong indications of good EXAFS fits, validating the model of a mixture of two scattering phases. Notably, with increasing $x$, the main scattering phase shows subtle changes in the radial distance in Figure 12c, in contrast to the vividly increased $\sigma^{2}$ values in Figure $12 \mathrm{~d}$. Otherwise, with increasing $x$, the secondary scattering 
phase reveals a distinct change of radial distance in Figure 12e and an insubstantial variation of $\sigma^{2}$ values in Figure 12f. We deduce from these observations that the main scattering phase of the $x=0.4$ sample possesses more disorder than that of the $x=0.2$ sample. Additionally, the disorder degree of the secondary scattering phase is similar between the two cases $x=0.2$ and $x=0.4$.
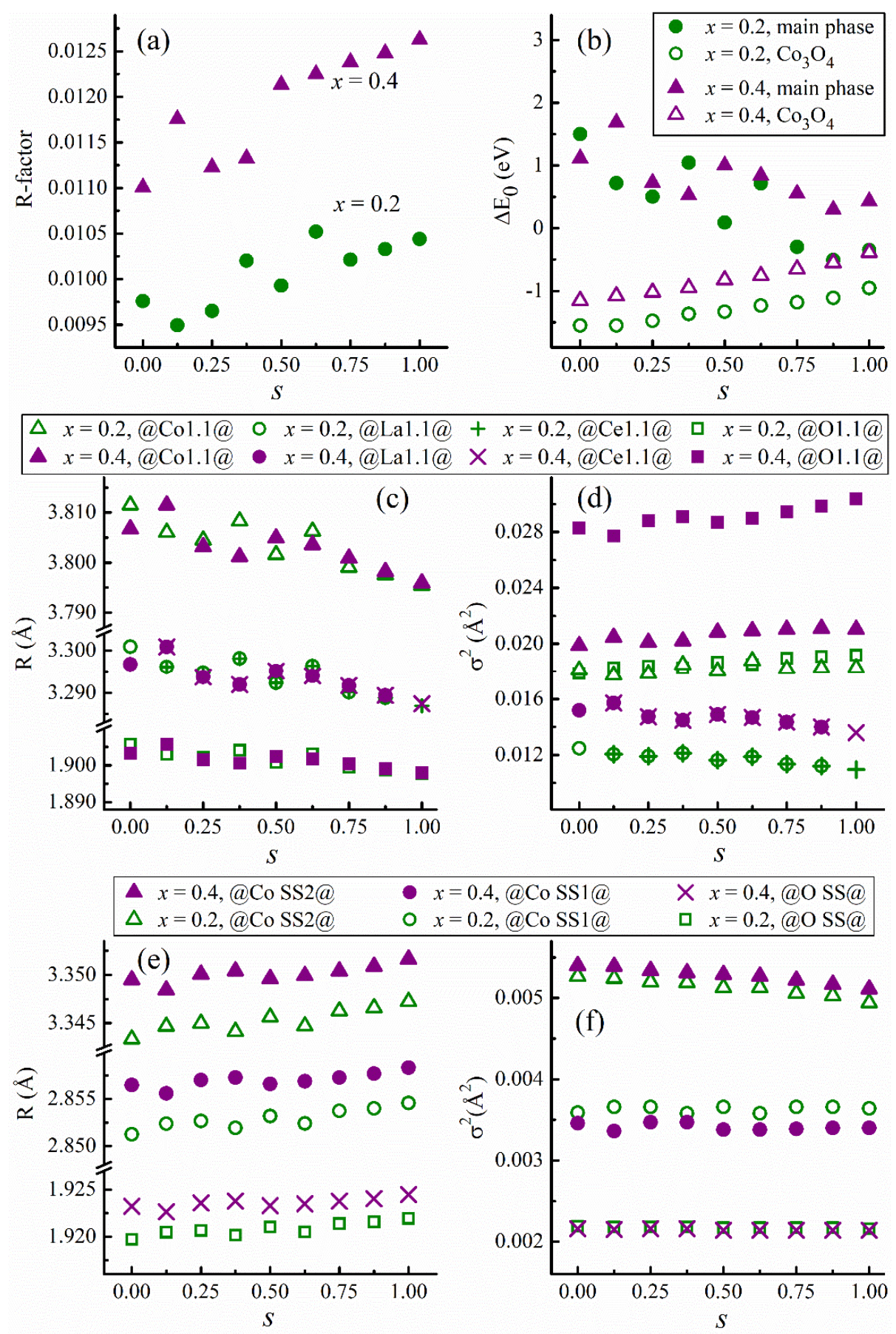

Figure 12. Fit indices and fitted parameters as a function of $s$, the fraction of cerium dopants in the cubic main phase, for EXAFS data of $\mathrm{La}_{1-x} \mathrm{Ce}_{x} \mathrm{CoO}_{3}$, with $x=0.2$, and 0.4. (a) $R$-factor. (b) $\triangle \mathrm{E}_{0}$. (c,d) respectively show the values for radial distance and $\sigma^{2}$ for scattering paths of the main scattering phase. (e,f) respectively show the values for radial distance and $\sigma^{2}$ for scattering paths of the $\mathrm{Co}_{3} \mathrm{O}_{4}$-like scattering phase. 


\section{Conclusions}

In summary, we applied a combination of XRD and XAS on $\mathrm{La}_{1-x} \mathrm{Ce}_{x} \mathrm{CoO}_{3}$ samples to reexamine the solubility of $\mathrm{Ce}$ into the host lattice and study metal-oxygen bonding states of these electron-doped materials. The central result of the current work is the observation of changes in the $\mathrm{Co}-\mathrm{O}$ bond and $\mathrm{La}-\mathrm{O}$ bond lengths in $\mathrm{LCO}$ upon the effect of Ce addition and the formation of the mixed Ce valence state. The model combining a cubic $\mathrm{LCO}$ with $\mathrm{Ce}^{4+} / \mathrm{Co}^{2+}$ dopants and a secondary phase provides the best Rietveld refinement fit to the XRD data. Further, the EXAFS fitting results of Co K-edge data also substantiate the Rietveld analysis. However, all the models studied did not capture the precise knowledge on the extent of Ce insertion, and thus this issue remains open. In particular, the XANES data showed that La $5 d$-band of the pristine LCO is slightly electron-filled and that of Ce-doped LCO is in a less occupied state. We explored this phenomenon by the ab initio calculation of electron energy distribution, using the model electron density derived from XRD experiments and formulae of the density functional theory. The results establish the marginally covalent $\mathrm{La}-\mathrm{O}$ bonding states of the pristine $\mathrm{LCO}$ in both rhombohedral and monoclinic lattice models and the nearly pure ionic $\mathrm{La}-\mathrm{O}$ bonding states in cubic Ce-doped LCO.

Author Contributions: D.-C.N.: Conceptualization, Project administration, Methodology, Investigation, Data curation, Validation, Formal analysis, Software, Visualization, Writing_original draft, Writing-review and editing. C.-C.C.: Investigation. A.K.A.: Investigation. C.-S.C.: Resources, Supervision, Validation, Writing-review and editing. C.-H.L.: Resources, Supervision, Validation, Writing - review and editing, Funding acquisition. All authors have read and agreed to the published version of the manuscript.

Funding: National Science Council of Taiwan. Contract No. 99-WFA-0400161.

Institutional Review Board Statement: Not applicable.

Informed Consent Statement: Not applicable.

Data Availability Statement: The data presented in this study are available within the article.

Acknowledgments: We thank Duc-Long Nguyen, Tung Hsu, and Peng-Jen Chen for fruitful discussions and technical assistance. We acknowledge the Taiwan Light Source (NSRRC) for provision of beam time. This work was supported by the National Science Council of Taiwan, under Contract No. 99-WFA-0400161.

Conflicts of Interest: The authors declare no conflict of interest.

\section{References}

1. Hwang, J.; Rao, R.R.; Giordano, L.; Katayama, Y.; Yu, Y.; Shao-Horn, Y. Perovskites in catalysis and electrocatalysis. Science 2017, 358, 751-756. [CrossRef] [PubMed]

2. Seh, Z.W.; Kibsgaard, J.; Dickens, C.F.; Chorkendorff, I.; Nørskov, J.K.; Jaramillo, T.F. Combining theory and experiment in electrocatalysis: Insights into materials design. Science 2017, 355, 6321. [CrossRef]

3. Fabbri, E.; Nachtegaal, M.; Binninger, T.; Cheng, X.; Kim, B.J.; Durst, J.; Bozza, F.; Graule, T.; Schäublin, R.; Wiles, L.; et al. Dynamic surface self-reconstruction is the key of highly active perovskite nano-electrocatalysts for water splitting. Nat. Mater. 2017, 16, 925-931. [CrossRef] [PubMed]

4. Zhu, H.Y.; Zhang, P.F.; Dai, S. Recent advances of Lanthanum-based perovskite oxides for catalysis. ACS Catal. 2015, 5, 6370-6385. [CrossRef]

5. Zeng, Z.C.; Xu, Y.S.; Zhang, Z.S.; Gao, Z.S.; Luo, M.; Yin, Z.Y.; Zhang, C.; Xu, J.; Huang, B.L.; Luo, F.; et al. Rare-earth-containing perovskite nanomaterials: Design, synthesis, properties and applications. Chem. Soc. Rev. 2020, 49, 1109-1143. [CrossRef] [PubMed]

6. Radaelli, P.G.; Cheong, S.-W. Structural phenomena associated with the spin-state transition in $\mathrm{LaCoO}_{3}$. Phys. Rev. B 2002, 66, 094408. [CrossRef]

7. Haas, O.; Struis, R.P.W.J.; McBreen, J.M. Synchrotron X-ray absorption of $\mathrm{LaCoO}_{3}$ perovskite. J. Solid State Chem. 2004, 177, 1000-1010. [CrossRef]

8. Phelan, D.; Louca, D.; Rosenkranz, S.; Lee, S.-H.; Qiu, Y.; Chupas, P.J.; Osborn, R.; Zheng, H.; Mitchell, J.F.; Copley, J.R.D.; et al. Nanomagnetic droplets and implications to orbital ordering in $\mathrm{La}_{1-x} \mathrm{Sr}_{x} \mathrm{CoO}_{3}$. Phys. Rev. Lett. 2006, 96, 027201. [CrossRef] 
9. Maris, G.; Ren, Y.; Volotchaev, V.; Zobel, C.; Lorenz, T.; Palstra, T.T.M. Evidence for orbital ordering in LaCoO 3 . Phys. Rev. B 2003, 67, 224423. [CrossRef]

10. Korotin, M.A.; Ezkov, S.Y.; Solovyev, I.V.; Anisimov, V.I.; Khomskii, D.I.; Sawatzky, G.A. Intermediate-spin state and properties of $\mathrm{LaCoO}_{3}$. Phys. Rev. B 1996, 54, 5309. [CrossRef]

11. Imada, M.; Fujimori, A.; Tokura, Y. Metal-insulator transitions. Rev. Mod. Phys. 1998, 70, 1039. [CrossRef]

12. Ishikawa, A.; Nohara, J.; Sugai, S. Raman study of the orbital-phonon coupling in LaCoO 3. Phys. Rev. Lett. 2004, 93, 136401. [CrossRef]

13. Haverkort, M.W.; Hu, Z.; Cezar, J.C.; Burnus, T.; Hartmann, H.; Reuther, M.; Zobel, C.; Lorenz, T.; Tanaka, A.; Brookes, N.B.; et al. Spin state transition in $\mathrm{LaCoO}_{3}$ studied using soft X-ray absorption spectroscopy and magnetic circular dichroism. Phys. Rev. Lett. 2006, 97, 176405. [CrossRef]

14. Merz, M.; Fuchs, D.; Assmann, A.; Uebe, S.; Löhneysen, H.v.; Nagel, P.; Schuppler, S. Spin and orbital states in single-layered La2-xCaxCoO4 studied by doping- and temperature-dependent near-edge X-ray absorption fine structure. Phys. Rev. B 2011, 84, 014436. [CrossRef]

15. Augustinský, P.; Křápek, V.; Kuneš, J. Doping induced spin state transition in $\mathrm{LaCoO}_{3}$ : Dynamical mean-field study. Phys. Rev. Lett. 2013, 110, 267204. [CrossRef]

16. Feygenson, M.; Novoselov, D.; Pascarelli, S.; Chernikov, R.; Zaharko, O.; Porcher, F.; Karpinsky, D.; Nikitin, A.; Prabhakaran, D.; Sazonov, A.; et al. Manifold of spin states and dynamical temperature effects in $\mathrm{LaCoO}_{3}$ : Experimental and theoretical insights. Phys. Rev. B 2019, 100, 054306. [CrossRef]

17. Park, H.; Nanguneri, R.; Ngo, A.T. DFT + DMFT study of spin-charge-lattice coupling in covalent LaCoO 3 . Phys. Rev. B 2020, 101, 195125. [CrossRef]

18. Medling, S.; Lee, Y.; Zheng, H.; Mitchell, J.F.; Freeland, J.W.; Harmon, B.N.; Bridges, F. Evolution of magnetic oxygen states in Sr-doped $\mathrm{LaCoO}_{3}$. Phys. Rev. Lett. 2012, 109, 157204. [CrossRef] [PubMed]

19. Zhang, Q.F.; Zhang, W.Y. Magnetic ground state of electron-doped $\mathrm{La}_{1-x} \mathrm{Ce}_{x} \mathrm{CoO}_{3}$ compounds. Phys. Rev. B 2003, 68, 184403. [CrossRef]

20. Fuchs, D.; Schweiss, P.; Adelmann, P.; Schwarz, T.; Schneider, R. Ferromagnetic order in the electron-doped system $\mathrm{La}_{1-x} \mathrm{Ce}_{x} \mathrm{CoO}_{3}$. Phys. Rev. B 2005, 72, 014466. [CrossRef]

21. Merz, M.; Nagel, P.; Pinta, C.; Samartsev, A.; Löhneysen, H.v.; Wissinger, M.; Uebe, S.; Assmann, A.; Fuchs, D.; Schuppler, S. X-ray absorption and magnetic circular dichroism of $\mathrm{LaCoO}_{3}, \mathrm{La}_{0.7} \mathrm{Ce}_{0.3} \mathrm{CoO}_{3}$, and $\mathrm{La}_{0.7} \mathrm{Sr}_{0.3} \mathrm{CoO}_{3}$ films: Evidence for cobalt-valencedependent magnetism. Phys. Rev. B 2010, 82, 174416. [CrossRef]

22. Qian, J.M.; Wang, T.T.; Zhang, Z.M.; Liu, Y.G.; Li, J.F.; Gao, D.Q. Engineered spin state in Ce doped LaCoO 3 with enhanced electrocatalytic activity for rechargeable Zn-air batteries. Nano Energy 2020, 74, 104948. [CrossRef]

23. Xu, X.M.; Wang, W.; Zhou, W.; Shao, Z.P. Recent advances in novel nanostructuring methods of perovskite electrocatalysts for energy-related applications. Small Methods 2018, 2, 1800071. [CrossRef]

24. Tsang, K.L.; Lee, C.H.; Jean, Y.C.; Dann, T.E.; Chen, J.R.; D'Amico, K.L.; Oversluizen, T. Wiggler X-ray beamlines at Synchrotron Radiation Research Center. Rev. Sci. Instrum. 1995, 66, 1812-1814. [CrossRef]

25. Lutterotti, L.; Matthies, S.; Wenk, H.-R.; Schultz, A.S.; Richardson, J.W. Combined texture and structure analysis of deformed limestone from time-of-flight neutron diffraction spectra. J. Appl. Phys. 1997, 81, 594-600. [CrossRef]

26. Thornton, G.; Tofield, B.C.; Hewat, A.W. A neutron diffraction study of $\mathrm{LaCoO}_{3}$ in the temperature range $4.2<\mathrm{T}<1248 \mathrm{~K}$. J. Solid State Chem. 1986, 61, 301-307.

27. Wold, A.; Ward, R. Perowskite-type oxides of cobalt, chromium and vanadium with some rare earth elements. J. Am. Chem. Soc. 1954, 76, 1029-1030. [CrossRef]

28. Roth, W.L. The magnetic structure of Co3O4. J. Phys. Chem. Solids 1964, 25, 1-10. [CrossRef]

29. Wyckoff, R.W.G. Crystal Structures, 2nd ed.; Interscience Publishers, Inc.: New York, NY, USA, 1963; Volume 1, pp. $239-444$.

30. Toby, B.H. R factors in Rietveld analysis: How good is good enough? Powder Diffr. 2006, 21, 67-70. [CrossRef]

31. Capehart, T.W.; Mishra, R.K.; Meisner, G.P.; Fuerst, C.D.; Herbst, J.F. Steric variation of the cerium valence in Ce2Fe14B and related compounds. Appl. Phys. Lett. 1993, 63, 3642. [CrossRef]

32. Li, Y.J.; Ohnishi, N.; Nakai, I.; Amakai, Y.; Murayama, S. X-ray absorption near edge structure of amorphous CexRu100-x. J. Phys. Soc. Jpn. 2009, 78, 904717. [CrossRef]

33. Kossoy, A.; Wang, Q.; Korobko, R.; Grover, V.; Feldman, Y.; Wachtel, E.; Tyagi, A.K.; Frenkel, A.I.; Lubomirsky, I. Evolution of the local structure at the phase transition in $\mathrm{CeO}_{2}-\mathrm{Gd}_{2} \mathrm{O}_{3}$ solid solutions. Phys. Rev. B 2013, 87, 054101. [CrossRef]

34. Minasian, S.G.; Batista, E.R.; Booth, C.H.; Clark, D.L.; Keith, J.M.; Kozimor, S.A.; Lukens, W.W.; Martin, R.L.; Shuh, D.K.; Stieber, S.C.E.; et al. Quantitative evidence for Lanthanide-Oxygen orbital mixing in CeO2, PrO2, and TbO2. J. Am. Chem. Soc. 2017, 139, 18052-18064. [CrossRef] [PubMed]

35. Tsirelson, V.G. Topological analysis of the experimental electron density. Can. J. Chem. 1996, 74, 1171-1179. [CrossRef]

36. Tsirelson, V.G. The mapping of electronic energy distributions using experimental electron density. Acta Crystallogr. B 2002, 58, 632-639. [CrossRef] [PubMed]

37. Momma, K.; Izumi, F. VESTA 3 for three-dimensional visualization of crystal, volumetric and morphology data. J. Appl. Crystallogr. 2011, 44, 1272-1276. [CrossRef] 
38. Ravel, B.; Newville, M. ATHENA, ARTEMIS, HEPHAESTUS: Data analysis for X-ray absorption spectroscopy using IFEFFIT. J. Synchrotron. Radiat. 2005, 12, 537-541. [CrossRef]

39. Calvin, S. XAFS for Everyone; CRC Press: Boca Raton, FL, USA, 2013.

40. Nguyen, D.C.; Chu, C.C.; Lee, C.H.; Lai, W.C.; Chang, C.S. Coercivity enhancement of FePd thin films prepared by the postannealing of off-stoichiometric magnetron-sputtered multilayers. J. Appl. Phys. 2018, 123, 073901. [CrossRef]

41. Ravel, B. Path degeneracy and EXAFS analysis of disordered materials. J. Synchrotron. Radiat. 2014, 21, 1269-1274. [CrossRef]

42. Kotani, A.; Jo, T.; Parlebas, J.C. Many-body effects in core-level spectroscopy of rare-earth compounds. Adv. Phys. 1988, $37,37-85$. [CrossRef]

43. Booth, C.H.; Walter, M.D.; Lukens, W.W.; Andersen, R.A. Self-contained Kondo effect in single molecules. Phys. Rev. Lett. 2005, 95, 267202. [CrossRef] [PubMed] 